\title{
OPIIMAL CAPITAL STRUCTURE AND REGULATORY CONTROL
}

\section{1}

Carlos Perez Montes.

Documentos de Trabajo N. 1128

\section{banco es españa}

\author{
Eurosistema
}


OPTIMAL CAPITAL STRUCTURE AND REGULATORY CONTROL 
OPTIMAL CAPITAL STRUCTURE AND REGULATORY CONTROL

Carlos Pérez Montes ${ }^{(*)}$

BANCO DE ESPAÑA

$\left.{ }^{*}\right)$ This work has benefited from the invaluable advice of Michael Riordan, and also from the contributions and comments of Yeon Koo Che, Katherine Ho, Bernard Salanie, Patrick Bolton, Raicho Bojilov and an anonymous referee. This article is partly developed from materials of my doctoral thesis at Columbia University. The views expressed on the article are those of the author and do not necessarily reflect those of the Bank of Spain. 
The Working Paper Series seeks to disseminate original research in economics and finance. All papers have been anonymously refereed. By publishing these papers, the Banco de España aims to contribute to economic analysis and, in particular, to knowledge of the Spanish economy and its international environment.

The opinions and analyses in the Working Paper Series are the responsibility of the authors and, therefore, do not necessarily coincide with those of the Banco de España or the Eurosystem.

The Banco de España disseminates its main reports and most of its publications via the INTERNET at the following website: http://www.bde.es.

Reproduction for educational and non-commercial purposes is permitted provided that the source is acknowledged.

() BANCO DE ESPAÑA, Madrid, 2011

ISSN: 0213-2710 (print)

ISSN: 1579-8666 (on line)

Depósito legal: M. 44026-2011

Unidad de Publicaciones, Banco de España 


\section{Abstract}

This article studies how the managers of a regulated firm can use debt and equity contracts to constrain the regulator's policy through the contingent transfer of control to external investors with high relative liquidation value. External finance increases regulated income and facilitates investment, but managers generally choose socially excessive levels of outside funds. If bankruptcy law favors reorganization over liquidation, the managers's value of debt for a given investment level decreases. In the presence of income risk, regulatory ex ante commitment can increase the firm's value if the regulator's preference for continuation is high relative to that of managers.

Keywords: Industrial regulation, capital structure, control rights, hold-up, bankruptcy.

JEL classification: L51, L52, G32, G33. 


\section{Resumen}

Este artículo estudia como los administradores de una empresa regulada pueden utilizar contratos de deuda y ampliaciones de capital para restringir la política del regulador por medio de la transferencia del poder de control sobre la empresa a inversores externos con un alto valor de liquidación. La financiación externa incrementa los beneficios regulados y facilita la inversión, pero los administradores de la empresa generalmente eligen un nivel socialmente excesivo de fondos externos. Si la ley concursal favorece la reorganización sobre la liquidación, el valor de la deuda para los administradores disminuye para un nivel dado de inversión. En presencia de riesgo sobre el beneficio de la empresa, el compromiso inflexible del regulador a una política que no reacciona al nivel de beneficios puede llevar a un incremento del valor de la empresa para los administradores si la preferencia del regulador por la continuidad de la empresa regulada es superior a la de estos.

Palabras claves: Regulación Industrial, estructura de capital, derechos de control, captura del inversor, derecho concursal.

Códigos JEL: L51, L52, G32, G33. 


\section{Introduction}

The capital structure literature has studied in detail how the contingent allocation of control rights between managers and investors can improve incomplete financial contracts and raise the value of firms, e. g., Hart and Moore (1989, 1998), Aguion and Bolton (1992) and Dewatripont and Tirole (1994). The relation between private control rights and the power of government regulation over certain business decisions of firms has not received a comparable amount of attention. In this article, I study the interaction of the rights over reorganization and liquidation granted by the financial contracts of a regulated firm with the regulator's control over the income of the firm. For example, debt contracts transfer control over operations and liquidation from managers to investors in the event of bankruptcy, and debtholders's protection under bankruptcy law can also limit the administrative control of the firm by the regulator. In this framework, I investigate (i) the ability and incentives of managers to constrain the regulator's policy through the use of financial contracts and (ii) the impact of different bankruptcy and regulatory regimes on the value of the firm and the welfare measured by the regulator.

I consider a regulated firm where private managers hold initially a full equity stake and can decide whether to liquidate or reorganize all or part of the firm's projects. A positive investment level is required to make the firm operational and the regulator controls partially the income yield of the firm. The financing of this investment is complicated by the presence of non verifiable private benefits for the managers and the capacity of the regulator to hold up the firm once the investment is committed. External financing creates a credible threat of transfer of control of the liquidation and reorganization decisions to investors with a lower interest in continuation of the firm's projects than the regulator or the owners-managers. External investors can only appropriate the verifiable income of the firm and they have therefore a lower continuation value than managers, who also derive private benefits, and the regulator, who also values consumer surplus. 
Regulators enjoy discretion to impact the income of firms in different sectors. For example, rate of return regulation and price cap regimes leave utility regulators freedom to manipulate the regulated income of the firms in their jurisdictions. ${ }^{1}$ The discretion of these regulators to disallow imprudent investment costs in the calculation of regulated income requirements is also significant, as accounted in Lyon and Mayo (2005) for the US electricity sector. If the income of a utility firm is high, the regulator will be pressed by consumer groups to reduce prices. The lack of ex-ante commitment power creates a hold-up risk for investors in regulated firms and it might prevent socially valuable investments. ${ }^{2}$

The liquidation of the assets of a bankrupt regulated firm is also a real possibility with detrimental consequences for consumers. For example, Washington Public Power Supply System (WPPSS) default in 1982 lead to the abandonment of four incomplete nuclear power plants, with partial repayments to bondholders funded by increases in consumer rates of the member utilities of WPPSS. ${ }^{3}$ In this case, the threat of costly liquidation in the bankruptcy procedure induced an upward revision of regulated prices that favored external investors at the cost of consumers. Ex ante, the use of debt might have facilitated the financing of a new technology with uncertain cost, as the investors could anticipate a higher degree of protection than with an equity contribution. Financial distress does not necessarily involve the dismantling of physical assets, but it might entail reorganization or a transfer of the assets of the regulated company to an external firm. The regulator might still be reluctant to enter the reorganization process, as it might affect the quality of service and force a revision of regulatory policy, e. g., the increase in regulated prices might be necessary to facilitate other concessions from creditors. On the contrary, the possible improvements of governance and operations associated to the reorganization process represent a potential benefit for regulators.

\footnotetext{
${ }^{1}$ The U.S. Supreme Court sentence on Hope Natural Gas (1944) set the reasonable rate doctrine that allows regulators to choose rates as long as they allow an adequate return on a well managed firm.

${ }^{2}$ See Salant and Woroch (1992) and Gilbert and Newbery (1994) for regulation with lack of commitment in a dynamic setting. Albuquerque and Hopenhayn (2004) study a dynamic capital structure choice problem. Che and Sakovics $(2004,2008)$ study the hold-up problem in a general framework.

${ }^{3}$ WPPSS was an association of several municipal utilities in Washington state. The default of WPPSS implied the reorganization of the association, but, at the project level, it implied the liquidation of multiple nuclear power plants. See Alexander et al. (1983) and Pope (2008) for historical details of the WPPSS default and Lyon and Mayo (2005) and Joskow et al. (1989) for analysis of the cost disallowances in the US electricity sector in the 1980s.
} 
The base model in the paper considers a regulator with deterministic control of the income of the regulated firm. If managers with high private benefits finance the firm with internal funds or new non-voting equity, they maintain their control rights. The regulator can then limit the firm's income to favor consumers without risking liquidation. The managers and external investors anticipate the low regulated income and they will have lower incentives to finance the initial investment in the firm.

The use of debt financing creates the possibility of bankruptcy and transfer of control over the liquidation decision to external investors. Leverage can then force the regulator to increase regulated income to avoid partial or total liquidation of the firm's assets. The capacity of leverage to force higher regulated income increases with the liquidation value and decreases with potential gains of reorganization through the bankruptcy process. The regulator anticipates that reorganization gains can generate additional verifiable income to compensate investors and reduces regulated income. The reorganization process following bankruptcy can also restrict private benefits and it will thus further reduce the strategic value of debt for managers for a given level of financing. The bankruptcy reorganization process can still increase the value of the firm for managers if it generates enough verifiable income to finance an investment that was not otherwise viable. The transfer of control to external equity holders through new voting equity can have the same effect as the use of debt if external equity holders can not acquire a big portion of the private benefits of managers.

The transfer of control rights to debtholders or external equity holders mitigates the hold-up problem by forcing regulators to avoid the bankruptcy procedure. The remedy is not perfect, as the firm's managers can also use debt to increase regulated income above the level required to sustain investment. Managers do not internalize the social costs of the increase in regulated income, e. g., high regulated utility rates cause monopolistic quantity distortions.

The basic model is extended with the addition of income risk. The income of the firm includes now a portion controlled by the regulator and a purely random component. For example, an utility firm is affected by shocks to technology and energy prices. If a regulator 
wants to ensure the continuation of the firm at all possible income states, it is forced to set the regulated portion of income so that the value of continuation exceeds that of liquidation even at the lowest income state. Alternatively, the regulator might find optimal to allow liquidation at low income states to reduce the average regulated income. The strategic value of the capital structure in this setting depends on the relative preference for continuation of the regulator and the managers. If the regulator is highly averse to liquidation of the firm's assets, the use of debt will force higher regulated income than in the base case. If the managers are highly averse to liquidation, they will reduce the level of leverage to make this event less likely.

In this setting, it is not necessarily optimal to have the regulator committed to a particular policy before the income state is known. The possibility to adjust policy ex post might allow the regulator to achieve a higher total welfare by ensuring continuation at all income states and avoiding excessive regulated income at high income states. The cost of this lack of commitment is that the managers have no incentive to contain debt, as the regulator will be able to adjust regulated income to ensure continuation for a given level of leverage.

The need to cover the investment costs of regulated firms is recognized since at least the early work of Boiteux (1956). The modern industrial regulation literature, e. g., Baron and Myerson (1982) and Laffont and Tirole (1986), incorporates profit requirements derived from investment needs in the participation constraint of the firm and focuses on informational problems. In this literature, the incentives of a regulated monopolist to invest in efficiency have also been studied in articles such as Riordan (1987) and Tirole (1986). The surveys in Baron (1989), Laffont and Tirole (1993) and Armstrong and Sappington (2007) reveal that the works studying the capital structure of regulated firms are more scarce.

The closest references to this problem in the regulation literature are Spiegel and Spulber (1994, 1997) and Dasgupta and Nanda (1993). In these articles, the bargaining effect of 
capital structure, and debt in particular, originates from the presence of bankruptcy costs in the firm (legal fees and reorganization). These papers are implicitly considering bankruptcy regulation that imposes mandatory and costly reorganization. In the US legal system, the creditors of a firm would be compelled to file for Chapter 11 if the firm fails to honor its debt. The regulator internalizes (at least partially) the costs of the bankruptcy procedure and reduces the likelihood of financial failure by allowing higher regulated prices.

The current article allows the party with the control of the firm to choose whether to initiate the bankruptcy procedure rather than imposing automatic reorganization. This bankruptcy procedure can be interpreted as reorganization or liquidation and accommodate both the Chapter 11 and Chapter 7 regimes in the US bankruptcy code. Debt can still constrain the regulator even if there are no explicit bankruptcy costs, i. e., no positive difference between firm's continuation value and the value under the most favorable bankruptcy procedure, as investors have greater incentives to liquidate the business. The existence of an optimal capital structure depends rather on the conflict of interest between the investors, managers and the regulator.

Faure-Grimaud (1997) also considers the interaction between financial markets and industrial regulation. In that article, the regulated firm can deteriorate the profits of its competitors with a costly predatory action and the incentive to do so depends on the regulatory regime in place. Financial markets enter the model through the use by the competitors of the regulated firm of incomplete financial contracts to obtain financing, in an adaptation of the model in Bolton and Scharfstein (1990). In the current article, the regulated firm makes strategic use of its own financial contracts.

The focus in the corporate finance literature, Aghion and Bolton (1992), Hart and Moore $(1989,1998)$ and Dewatripont and Tirole (1994) is on the characterization of bilateral efficient contracting between external investors and inside management. The main interest of the current article is the study of the externalities that the financial contracts of the firm impose on a third party (consumers) and its strategic effect on the actions of an external agent (the 
regulator). ${ }^{4}$ The financial contracting framework considered is close to Aghion and Bolton (1992), with bankruptcy contingent on verifiable variables and a discrete decision for the party in control. ${ }^{5}$ Hart and Moore $(1989,1998)$ analyze bilateral bankruptcy renegotiation in a different setting where firm's assets work as collateral and facilitate additional future investments. Debt financing allows the investors to seize this valuable collateral and provides them with higher bargaining power in the bankruptcy procedure. Dewatripont and Tirole (1994) study the use of capital structure to create a probability of investor interference with management and induce managerial effort. In that article, the optimal capital structure trades off effort inducement and inefficient interference.

The empirical financial literature, starting with Baxter (1967),Warner (1977) and Haugen and Senbet (1978), has found a moderate size of direct bankruptcy costs. Hotchkiss et al. (2007) report a range of estimates in this literature in between $1 \%$ and $10 \%$ of assets existing previous to financial distress. Indirect costs can increase the burden of bankruptcy and are a function of regulation, as presented in Jensen (1991). The estimates of indirect costs also range widely. Andrade and Kaplan (1998) find that indirect costs of financial distress are small in the absence of a negative economic shock. Altman (1984) estimates indirect costs equal to $10 \%$ of the value of the firm, but he can not separate the financial and economic components in these estimates. The current article provides a theory that creates a role for the capital structure of the regulated firm even if the bankruptcy costs of the firm are small.

The rest of the paper proceeds as follows. Section 2 presents the base model with no income risk and Section 3 analyzes equilibrium capital structure and regulation. Section 4 introduces risk in the income of the firm and reexamines the managers's choice of capital structure and regulation policy. Section 5 concludes.

\footnotetext{
${ }^{4}$ The study of control rights is encompassed into the broader optimal capital structure literature reacting to the Modigliani and Miller (1958) result on the value irrelevance of the capital structure. See the early contributions of Jensen and Meckling (1976), Myers (1977), Ross (1977) and Townsend (1979).

${ }^{5}$ Aghion and Bolton (1992) study efficient bilateral contracts in a general setting with different assumptions on the correlation of private benefits and total returns and the verifiability of income. The current work uses a specific return structure for the firm adapted closely to analyze bankruptcy and incorporates the regulator's policy problem.
} 


\section{Base Model}

The main elements of the model include the market and cost conditions in which the regulated firm operates, the payoffs of the regulator, managers and investors, and the temporal structure. I define each of these elements in turn.

\section{The Firm}

There is a single firm with the opportunity to invest $K$ to acquire technology and equipment with application to two different sectors. For example, telephone companies can offer basic telephone services and mobile telephone services. I assume that the income from activities in the first sector depends on a regulatory decision over quantity $q$ whereas the income from the second sector is given exogenously. ${ }^{6}$

The verifiable income from the unregulated sector is exogenously fixed at $\bar{\pi}>0$ and the private benefits associated to the management of the firm are fixed at $B>0$. The private benefits $B$ can include non-pecuniary elements and non-verifiable income. Regulated income is given by the function $\pi(q)$, where $q$ is a regulated quantity that is defined over the interval $[0, \bar{q}]$, for $\bar{q} \in \mathbb{R}^{+}$. For example, the quantity $q$ can correspond to the level of coverage, i. e., the number of users, of a telephone or an electricity firm. The underlying inverse demand and cost functions, $p(q)$ and $C(q)$ such that $\pi(q)=p(q) q-C(q)$, satisfy the following conditions:

(i) $p(q)$ is $C^{2}, p(q)>0$ and $\partial p(q) / \partial q=p^{\prime}(q)<0$ on $[0, \bar{q}]$.

(ii) $C(q)$ is $C^{2}, \partial C(q) / \partial q=C^{\prime}(q)>0$ and $\partial C(q) / \partial q^{2}=C^{\prime \prime}(q) \geq 0$ on $[0, \bar{q}]$.

(iii) $p(0)-C^{\prime}(0)>0$.

The firm can be operated to obtain verifiable income $\bar{\pi}+\pi(q)$ and private benefits $B$ or enter into a liquidation process with three main features: first, it overrules the regulatory control over $q$ and generates a total verifiable value $L$; second, it supresses private benefits $B$ and; third, it produces no consumer surplus. The amount $L$ is the maximum value that

\footnotetext{
${ }^{6}$ The second sector can also be regulated to some extent. For example, utilities are subject to environmental and safety regulation even in competitive sectors. The important assumptions are that (i) the two sectors are regulated separately (ii) and regulation in the second sector does not react to the firm's income and financial strategy.
} 
investors can attain through partial or total liquidation of the firm's assets. The liquidation process does not necessarily shuts down the firm, but the scaling down of the firm's assets is detrimental to consumers and the collection of private benefits. ${ }^{7}$

I assume that it is not (at least weakly) efficient to invest $K$ to obtain liquidation value $L$ and that exogenous income $\bar{\pi}$ does not avoid liquidation: $\bar{\pi} \leq L \leq K$. I further assume that there are quantity levels $q_{L}^{*}$ and $q_{K}^{*}$ such that the verifiable value of the firm exceeds investment cost $K$ and liquidation value $L$. If $\pi(q)$ is concave, this implicitly assumes that monopoly quantity $q_{m}$ satisfies $q_{m} \leq q_{K}^{*} \leq q_{L}^{*}$, with $\pi\left(q_{m}\right)+\bar{\pi}-K \geq 0 .{ }^{8}$ Condition (iii) guarantees that $q_{m}>0$.

\section{The Regulator}

The consumer surplus generated by the activities in the regulated sector is given by the non-negative function $C S(q)$, which is $C^{2}$ and has a first derivative $C S^{\prime}(q)>0$ given condition (i). The consumer surplus from the unregulated sector is exogenously fixed at $\overline{C S}>0$. I allow for the possibility that the regulator is more concerned about consumer surplus than the income of the firm by assuming an objective function $W(q)$ such that:

$$
W(q)=\alpha \cdot(\pi(q)+\bar{\pi}-K)+\overline{C S}+C S(q)
$$

where $\alpha \in[0,1]$ weights the preference of the regulator toward consumers. The statues of the regulator exclude the private benefits of managers $B$ from the welfare computation.

The regulator has the authority to choose the quantity $q$. Given the assumptions on $\pi(q)$ and $C S(q)$ and the support of $q$, the optimal quantity $q_{r}$ that maximizes $W(q)$ is guaranteed to exist. This quantity $q_{r}$ exceeds the monopoly quantity $q_{m}$ and it can be at the boundary of the support, i. e., $q_{r}=\bar{q}$, if $C S(q)$ increases sufficiently fast. ${ }^{9}$ To facilitate the analysis, I guarantee that $W(q)$ and $\pi(q)$ are concave by imposing the following condition on $p^{\prime \prime}(q)$ :

\footnotetext{
${ }^{7}$ The analysis is not substantially altered if liquidation does not suppress the private benefits and consumer surplus entirely. For example, I could assume liquidation brings negative shocks $\Delta B<0$ and $\Delta C S<0$.

${ }^{8}$ These quantities would be defined by the expressions $q_{L}^{*} \equiv \max q$ such that $\pi\left(q_{L}^{*}\right)+\bar{\pi}-L=0$ and $q_{K}^{*} \equiv \max q$ such that $\pi\left(q_{K}^{*}\right)+\bar{\pi}-K=0$. If there are multiple quantities that yield the same profit, the higher quantity Pareto dominates the lower one, which it is then discarded.

${ }^{9}$ Given $C S^{\prime}(q)>0$ in $[0, \bar{q}]$, we obtain that $\alpha \cdot \pi^{\prime}\left(q_{m}\right)+C S^{\prime}\left(q_{m}\right)=C S^{\prime}\left(q_{m}\right)>0$ and the regulator expands quantity $q$ beyond the monopolistic level $q_{m}$.
} 


$$
\frac{(2 \cdot \alpha-1) \cdot p^{\prime}(q)-\alpha \cdot C^{\prime \prime}(q)}{(1-\alpha)}<p^{\prime \prime}(q) \cdot q<C^{\prime \prime}(q)-2 \cdot p^{\prime}(q)
$$

Concavity of $\pi(q)$ and $W(q)$ ensures that $q_{r}$ and $q_{m}$ are uniquely defined. The Appendix A derives condition (2) and proves that the bounds on $p^{\prime \prime}(q) \cdot q$ are well-defined.

The preference for consumer surplus over the income of the firm might lead to negative regulated income at the quantity $q_{r}$. This outcome can be ruled out if $\alpha \cdot \pi^{\prime}\left(q_{0}\right)+C S^{\prime}\left(q_{0}\right)<0$ at the maximum quantity $q_{0}>q_{m}$ at which $\pi\left(q_{0}\right)=0$. For given $\pi(q)$ and $C S(q)$, this would involve placing a bound $\alpha_{0}=-C S^{\prime}\left(q_{0}\right) / \pi^{\prime}\left(q_{0}\right)$ such that $\alpha \geq \alpha_{0}$.

The project is socially beneficial for $q=q_{m}$. That is, $\pi\left(q_{m}\right)+\bar{\pi}-K+B+\overline{C S}+C S\left(q_{m}\right)>0$. This follows from previous assumptions: $B>0, \overline{C S}>0, \pi\left(q_{m}\right)+\bar{\pi}-K>0$ and $C S\left(q_{m}\right)>0$. The positivity of all these terms also implies that $W\left(q_{m}\right)$ is positive even if the regulator excludes private benefits $B$ :

$$
W\left(q_{m}\right)=\alpha \cdot\left(\pi\left(q_{m}\right)+\bar{\pi}-K\right)+\overline{C S}+C S\left(q_{m}\right)>0
$$

This also implies that the regulator does not want to liquidate the project once the investment cost is sunk, as $L \leq K$ and the relative gain of continuation with respect to liquidation is at least as big as $W\left(q_{m}\right)$. The regulator might be willing to implement a project with $q_{r} \leq q<q_{m}$ and negative social value if $\alpha$ is sufficiently low. However, managers and investors would not finance such projects, as it is presented below.

\section{The Managers and the Investors}

I assume that both the managers and the external investors are risk neutral. For a given regulated quantity $q$, the payoff from continuation of the firm for managers with a full equity stake can then be written as $U_{m}(q)=\pi(q)+\bar{\pi}+B-K$. The external investors can not claim private benefits $B$. An investor that appropriates the full verifiable income of the project receives then $U_{I}(q)=\pi(q)+\bar{\pi}-K$. 
The managers are assumed to have an initial full equity stake in the firm and cash at hand equal to $A<K$, so they are forced to use the capital markets if the project is to be executed. The lending activity in the capital market is perfectly competitive and, for simplicity, all agents are assumed to have a discount factor of 1 .

The managers would be willing to invest and continue operations at the quantity level $q_{r}: \pi\left(q_{r}\right)+\bar{\pi}+B-K>0$. The external investors do not internalize private benefits $B$ so they would require the verifiable value of the firm to cover the investment costs. I assume that $\pi\left(q_{r}\right)+\bar{\pi}<L \leq K$ to create a difference in the preference for continuation of managers and investors at the optimal regulated quantity $q_{r}$ and make the problem interesting.

\section{Temporal Structure}

I assume that regulators cannot commit ex ante to setting a certain quantity $q$. The managers are free to choose capital structure and this decision is less flexible than the regulatory choice. The regulator can therefore adjust the quantity $q$ to the choice of capital structure of the firm. The regulator is not constrained ex post by the recovery of the investment cost, but the continuation decision. The resulting order of moves is as follows:

At stage 0 , the managers choose whether to execute the project and they offer a contract to the financial market that determines capital structure. At stage 1, investors accept or reject the proposal of the managers to finance the project. At stage 2, the regulator chooses the regulated quantity and the payoffs for all the agents are determined, but they are not collectable at this stage. At stage 3 , the controlling investors decide whether to liquidate the firm. Finally, payoffs are collected at stage 4. I depict the order of moves in Figure 1. The solution concept employed is subgame perfect equilibrium (SPE). The game is of finite length, allowing to find the equilibrium by simple application of backward induction. 


\section{Equilibrium Capital Structure and Regulation}

I proceed in this section by considering the different financial contracts that can be proposed by the managers and determine the equilibrium quantities, investment levels, income and welfare associated with these contracts. I identify in this way the optimal capital structure for managers and compare the equilibrium welfare with the regulator's optimal welfare level.

It is instructive to consider first what would be the resulting outcome if managers hoarded enough cash and they decided to fully fund the project. After the investment is committed, the regulator sets its preferred quantity $q_{r}$, knowing that it ensures the continuation of the firm, as $U_{m}\left(q_{r}\right)=\pi\left(q_{r}\right)+\bar{\pi}+B-K>0$. The downweighting of the firm's income by the regulator does not lead to a critical hold-up problem, as the managers still find in their best interest to carry out the investment in the firm. The welfare level computed by the regulator attains its maximal value $W\left(q_{r}\right)$. I consider next the effects of the different forms of external financing with respect to this benchmark.

\subsection{Non-voting Equity}

The issuance of non-voting equity to cover the gap $S \equiv K-A$ would keep the original managers in control of the firm and the regulator will act accordingly by setting the ex post regulated quantity to $q_{r}$. If external shareholders appropriate a share $s_{e}$ of verifiable income, the managers prefer continuation, as $B \geq L-\pi\left(q_{r}\right)-\bar{\pi}>0$ implies $B>\left(1-s_{e}\right)$. $\left(L-\pi\left(q_{r}\right)-\bar{\pi}\right)$. The regulator will have no incentive to distort quantity $q_{r}$.

The shareholders that keep the newly issued non-voting equity know that they will receive at most $\bar{\pi}+\pi\left(q_{r}\right)$ from the investment, so they will refuse to provide the necessary funds if $S>\bar{\pi}+\pi\left(q_{r}\right)$. Conditional on the cash available in the firm, the following scenarios are possible:

(a) If $S \leqslant \bar{\pi}+\pi\left(q_{r}\right)$, the firm is funded. The managers receive $U_{m}\left(q_{r}\right)$. The new shareholders receive a zero net payoff from the assumption of perfectly competitive financial markets. The social welfare evaluated by the regulator is at its highest possible value $W\left(q_{r}\right)$. 
(b) If $S>\bar{\pi}+\pi\left(q_{r}\right)$, the firm is not funded. There is no surplus, so managers, potential shareholders and consumers receive all a zero payoff. In particular, non voting equity can not be raised for any level of cash needs $S>0$ if the weight $\alpha$ on the firm's income is low and $\bar{\pi}+\pi\left(q_{r}\right) \leq 0$.

Note also that competitive lending implies that the managers would be indifferent between issuing non-voting equity for a value $\bar{\pi}+\pi\left(q_{r}\right)$ and fully funding the project if they had enough funds to cover the investment, i. e., $S=0$. I summarize these results in the following lemma:

Lemma 1. The maximal amount of funds that the firm can raise in external non-voting equity is the maximum of $\bar{\pi}+\pi\left(q_{r}\right)$ and zero. This financial instrument involves no distortion in the optimal regulatory policy.

Proof. See discussion above

\subsection{Debt}

\section{Regulator's policy}

The use of debt creates the possibility of bankruptcy. However, the regulator has the ability to control perfectly regulated income, so it can also control the events of bankruptcy and liquidation. The question is whether the regulator has incentives to restrict quantity $q_{r}$ as a response to an increase in the leverage of the firm. A first observation is that for a level of debt below $\pi\left(q_{r}\right)+\bar{\pi}$, debt is equivalent to non-voting equity and Lemma 1 applies. For levels of debt $D$ above $\pi\left(q_{r}\right)+\bar{\pi}$, the use of the regulator's preferred quantity $q_{r}$ leads to bankruptcy, as $D>\pi\left(q_{r}\right)+\bar{\pi}$, and to liquidation, as $L>\pi\left(q_{r}\right)+\bar{\pi}$. The debtholders do not internalize the foregone consumer surplus and initiate liquidation to recover the biggest possible fraction of their investment. In Section 2, I assumed that the regulator can avoid liquidation by restricting production to $q_{L}^{*}$ and that he will strictly prefer to induce this distortion over the liquidation outcome. As long as debt $D$ is lower than the liquidation value $L$, it is preferable for the regulator to avoid bankruptcy, as it requires a smaller welfare loss. 


\section{Capital Structure and the Value of the Firm}

Given the strategy of the regulator discussed above, I consider the use of debt by managers with differing cash needs. If cash needs $S \equiv K-A$ are exactly covered with debt financing, $D=S$, I have the following scenarios:

(a) If $S \leqslant \pi\left(q_{r}\right)+\bar{\pi}$, an amount of debt $D=S$ is equivalent to non-voting equity and the results on the value of the firm in the previous subsection apply.

(b) If $\pi\left(q_{r}\right)+\bar{\pi}<S \leqslant L$, the regulator is forced to restrict the regulated quantity $q$ to $q_{D} \equiv \max q$ such that $\pi(q)+\bar{\pi}=D=S$. This leaves a level of utility equal to $U_{m}\left(q_{D}\right)=\pi\left(q_{D}\right)+\bar{\pi}+B-K$ to the managers. The debtholders receive a net zero payoff. The welfare value for the regulator is below its optimal level: $W\left(q_{D}\right)<W\left(q_{r}\right)$.

(c) If $L<S$, it is not possible to finance the project with all debt since debtholders obtain a maximum ex post repayment $L$. The excess of debt over liquidation value does not force further increases in regulated income, as the regulator only needs to make controlling debtholders indifferent between continuation and liquidation. If cash needs are at that high level, the hold-up problem persists and prevents a socially beneficial investment.

The use of debt reduces the cash contributions of managers, as it forces the regulator to increase regulated income $\pi(q)$ and cover ex-post a higher fraction of the investment cost $K$. The strategic value of debt can lead to the socially excessive use of this financial instrument even if net investment needs $S$ are strictly lower than the liquidation value $L$. If $S<L$, the managers of the firm must decide whether to limit the debt issue to financial needs $S$ or expand leverage with an additional amount of debt $L-S$ :

(d) If debt is limited to financial needs $S$, the value that the managers achieve is equal to $\pi\left(q_{S}\right)+\bar{\pi}+B-K$ for $\pi\left(q_{S}\right)+\bar{\pi}=\max \left(\pi\left(q_{r}\right)+\bar{\pi}, S\right)$. The $\max (.,$.$) term captures that$ financial needs might be lower than the level of income preferred by the regulator, $\pi\left(q_{r}\right)+\bar{\pi}$, and impose no distortion. For $S>\pi\left(q_{r}\right)+\bar{\pi}$, the distortion in $q_{r}$ still implies a welfare loss of size $W\left(q_{r}\right)-W\left(q_{S}\right)$. 
(e) If the managers increase debt up to $D=L$, the fraction of investment costs covered by the debtholders is maximal and the regulator is forced to restrict quantity to $q_{L}^{*}$. The managers receive then $\pi\left(q_{L}^{*}\right)+\bar{\pi}+B-K$. The welfare loss for the regulator is greater than in the case where debt only covers financial needs: $W\left(q_{r}\right)-W\left(q_{L}^{*}\right)>W\left(q_{r}\right)-W\left(q_{S}\right) \geq 0$ for $S<L$.

The managers will then choose to fund the project with an amount of debt in excess of the actual cash needs $S$ and retain a higher fraction of their own cash reserves $A$. In fact, I could modify the relative ranking of liquidation value and investment cost so that $L>K$. In this case, the managers would borrow more than the amount required to cover the cost of investment and use the extra cash to pay themselves a dividend, as the regulator will be forced to compensate investors to avoid liquidation. This creates a rationale to limit the use of debt by regulated firms to the needs of investment. Howe (1982), Phillips (1988) and Taggart (1985) describe the historical development of capital restrictions on public utilities in the United States. I gather all these observations in the following proposition for the equilibrium choice of debt.

Proposition 1. If available financial contracts include non-voting equity and debt, the value of the managers's position in the firm is maximized by issuing an amount of debt equal to liquidation value $L$. This level of leverage also implies:

(i) An increase in financing capacity from $\max \left(\pi\left(q_{r}\right)+\bar{\pi}, 0\right)$ to $L$, as the hold-up problem is attenuated.

(ii) An increase in welfare when $S>\pi\left(q_{r}\right)+\bar{\pi}$, as the socially valuable firm can be financed for lower amounts of cash reserves.

(iii) An excess amount of debt from the perspective of the regulator of size equal to $L-S$ is raised when cash needs fall short of the liquidation value, $S<L$.

Proof. See discussion above

The regulator might use an initial transfer to cover the investment needs of the firm rather than distorting the quantity $q$ towards the monopoly level. If these transfers were 
available, the relative reliance of the regulator on each of these instruments would depend on the comparison of the public cost of the quantity distortions at $t=2$ and the use of public funds at $t=1$. If the managers posses private information with respect to the cash available, or they can divert part of these reserves, a new agency cost arises, as the regulator must offer incentive compatible subsidies and quantities.

Combinations of non-voting equity and debt above $\pi\left(q_{r}\right)+\bar{\pi}$ are unfeasible. I denote non-voting equity as $E$ and consider first the scenario with $E+D>\pi\left(q_{r}\right)+\bar{\pi}$. Debt is senior to equity and it has a priority claim over the income of the firm. If $D>\pi\left(q_{r}\right)+\bar{\pi}$, the regulator sets $\pi\left(q_{D}\right)=D-\bar{\pi}$ and no surplus is left for equity holders. If $D<\pi\left(q_{r}\right)+\bar{\pi}$, the surplus left is still insufficient to cover the funds provided by equity holders. There is no increase in financing capacity by using a mix of debt and non-voting equity.

\subsection{Voting Equity}

There are several assumptions that can be applied to the private benefits of external equity holders with control rights. I will focus on the case in which these investors derive no private benefit and the managers maintain their private benefits $B$ as long as there is no liquidation. For example, pension funds and mutual funds usually stay away from the daily operations, and managers can keep the benefits associated with control. In this case, the use of voting equity would force the regulator to set quantity $q$ to $q_{L}^{*}$ in the exact same way as a debt position equal to $L$. External equity holders try to maximize their share of verifiable income and require a continuation value $L$ to maintain the firm in operation.

The transfer of control to external investors might require only the issue of a small amount of equity depending on the initial position of managers and external equity holders (assigning a golden share to an external investor would also suffice). However, the need to finance $S \equiv K-A$ remains and the managers can raise this quantity from a mix of debt, non-voting equity and voting equity. If control is transferred to external equity holders, the composition of the mix will have no further effect on financing capacity, as the liquidation 
value remains at $L .{ }^{10}$ The different claimholders will divide $\pi\left(q_{L}^{*}\right)+\bar{\pi}$ according to their relative contributions to the liabilities $L$.

Lemma 2. The transfer of control to external investors through the issue of new voting equity produces the same social welfare and value of the firm as an amount of debt L. As long as control is transferred to external equity holders, all the combinations of financial instruments used to cover $S$ imply the same value of the firm and social welfare.

Proof. See discussion above

The result above hinges on the assumption that the control of the board by external equity holders does not deprive the managers of the firm from their private benefits. I could assume instead that external equity holders can either appropriate the private benefits of managers or suppress them altogether. I consider these scenarios in turn:

(a) If the new controlling shareholders acquire private benefits $B$, they have the same incentives to continue in business as the former managers and the regulator will set the regulated quantity to $q_{r}$. The results of Lemma 1 on the value of the firm and the regulator's measure of welfare will apply. However, the financing capacity of the firm is increased to $\pi\left(q_{r}\right)+\bar{\pi}+B$, as external investors can appropriate greater benefits. This scenario assumes that voting equity makes $B$ verifiable and it therefore simplifies the investment problem.

(b) If the new controlling shareholders suppress private benefits, the regulator is still forced to set regulated income $\pi\left(q_{L}^{*}\right)=L-\bar{\pi}$. The results in Proposition 1 in terms of financing capacity and welfare are maintained. However, the value of the firm for managers decreases as the private benefits $B$ are lost. This value would equal now $\pi\left(q_{L}^{*}\right)+\bar{\pi}-K \equiv$ $L-K \leq 0$. The managers would therefore opt not to start the project if voting equity of this class is the only financial instrument available.

\footnotetext{
${ }^{10}$ The study of the optimal number of lenders is a separate topic outside of the scope of the current article. See Bolton and Scharfstein (1996) or Thakor (1996) for examples in this literature.
} 


\subsection{Bankruptcy and Reorganization of the Firm}

The liquidation of the firm's assets is the basic bankruptcy procedure considered in this article. The analysis would not be substantially altered if reorganization is detrimental to consumers. However, an alternative scenario arises when I consider reorganization neutral or beneficial to consumers such as an internal turnaround or expansion in the unregulated sector. This process might be initiated under the filing of Chapter 11 or be the consequence of the transfer of control to external shareholders. The loss of control by the managers turns them into subordinates of the controlling administrators.

The reorganization will be modeled as an increase in verifiable income $R$ and a reduction of private benefits to $\phi(B)<B$ that is not voluntarily adopted by the managers, i.e., $R-(B-\phi(B))<0$. This condition can be rationalized as the outcome of the delegated implementation of reforms in the firm by managers. Reform implementation can be analyzed in a principal-agent setting where the controlling administrators offer to the managers wages and probabilities of contract renewal contingent on the success of reform. ${ }^{11}$

For a given amount of debt $D$ and regulated income, the investors can now use the reorganization process to increase verifiable income in an amount $R$ at stage $t=3{ }^{12}$ The regulator anticipates then that a lower distortion in $q$ is needed to avoid the liquidation of a firm that goes into bankruptcy. With internal reorganization, the quantity required to avoid liquidation for debt level $D$ is $q_{D}^{r}$ and it is defined by $D-\bar{\pi}-R=\pi\left(q_{D}^{r}\right)<\pi\left(q_{D}^{n r}\right)=D-\bar{\pi}$ and $q_{D}^{r}>q_{D}^{n r}$, where $q_{D}^{n r}$ is the quantity without internal turn-around. The investors are still able to collect their claim in full with the new process, but a portion of this claim is covered now by reorganization gains rather than regulated income.

The term $R$ increases the critical level of debt above which the regulator is forced to restrict $q$ below $q_{r}$ from $\pi\left(q_{r}\right)+\bar{\pi}$ to $\pi\left(q_{r}\right)+\bar{\pi}+R .^{13}$ If $\pi\left(q_{r}\right)+\bar{\pi}+R<L$, the maximum

\footnotetext{
${ }^{11}$ This extended analysis is completed in an appendix available from the author.

${ }^{12}$ I assume that the investors's policy or the legal regime favors reorganization over liquidation if both processes allow to collect a given claim in full.

${ }^{13}$ If $R$ enters (1), the regulator might choose $q>q_{r}$ for $D \leq \pi\left(q_{r}\right)+\bar{\pi}$ to gain $\alpha R$ at the cost of a moderate distortion in $q$. This would not alter the argument in the text as, in this case, $D \leq \pi\left(q_{r}\right)+\bar{\pi}$ is dominated for managers by an issue of non voting equity $E=D$, and it is not an equilibrium capital structure.
} 
feasible level of debt remains at $L$, as the regulator still needs only to avoid liquidation rather than bankruptcy. If $\pi\left(q_{r}\right)+\bar{\pi}+R>L$, the firm can increase leverage further than in the base case as the total allowed verifiable income is higher. In all cases, the total funding capacity of the firm is not decreased by the introduction of this process. The presence of reorganization also improves consumer welfare through smaller reductions in the quantity $q$ for any level of debt $D$ in the range $\left[\pi\left(q_{r}\right)+\bar{\pi}, L\right]$.

Reorganization does not however Pareto dominate inaction, as it involves a reduction in the value of the position of managers of size equal to $R-(B-\phi(B))<0$. The managers will effectively compare the value of their position in the firm with and without reorganization. For $D>\pi\left(q_{r}\right)+\bar{\pi}$, the regulator will allow the firm to reorganize in order to minimize distortions in $q$. The maximum level of external financing that avoids reorganization is an issue of non-voting equity of size $\pi\left(q_{r}\right)+\bar{\pi}$, and the value of the firm under this restriction is $V_{0}=\pi\left(q_{r}\right)+\bar{\pi}+B-K$. All debt levels above $\pi\left(q_{r}\right)+\bar{\pi}$ involve the same reorganization cost and the only marginal effect of increases in leverage beyond this level is a weakly higher regulated income. ${ }^{14}$ The maximum value with reorganization will then equal $V_{L(r)}=L+\phi(B)-K$ if $\pi\left(q_{r}\right)+\bar{\pi}+R \leq L$ or $V_{R(r)}=\pi\left(q_{r}\right)+\bar{\pi}+R+\phi(B)-K$ if $\pi\left(q_{r}\right)+\bar{\pi}+R>L$. In all the scenarios, the managers are hurt with respect to the case with liquidation: $V_{L}=L+B-K$. To see this,

(a) $V_{L}-V_{0}=L-\pi\left(q_{r}\right)-\bar{\pi}>0$.

(b) $V_{L}-V_{L(r)}=B-\phi(B)>0$.

(c) $V_{L}-V_{R(r)}=\left(V_{L}-V_{0}\right)+\left(V_{0}-V_{R(r)}\right)=\left(L-\pi\left(q_{r}\right)-\bar{\pi}\right)+(B-\phi(B)-R)>0$.

If the cash needs are such that $S>\pi\left(q_{r}\right)+\bar{\pi}$, the managers can not finance the firm without engaging in reorganization. The managers will then be willing to continue the business of the firm only if $\max \left(V_{L(r)}, V_{R(r)}\right)>0$. If cash needs are moderate, $S \leq \pi\left(q_{r}\right)+\bar{\pi}$, managers might choose not to leverage as $V_{0}-V_{R(r)}=B-\phi(B)-R>0$, and $V_{0}-V_{L(r)}$ can

\footnotetext{
${ }^{14}$ Regulated income is only weakly higher because high reorganization benefits, $\pi\left(q_{r}\right)+\bar{\pi}+R>L$, can leave the regulator unconstrained.
} 
also be positive for high reorganization costs: $V_{0}-V_{L(r)}=\pi\left(q_{r}\right)+\bar{\pi}-L+(B-\phi(B))>0$ if $B-\phi(B)>L-\pi\left(q_{r}\right)+\bar{\pi}$. These considerations are summarized below:

Proposition 2. The possibility of reorganization in the bankruptcy procedure:

(i) increases (at least weakly) the maximum financing capacity of the firm.

(ii) increases the regulated quantity q, consumer surplus and the regulator's welfare measure if the firm is financed.

(iii) diminishes the value of the firm for the managers to $\max \left(V_{0}, V_{L(r)}, V_{R(r)}\right)<V_{L}$ for a firm's value $V_{L}$ with the liquidation only regime.

(iv) might induce managers to discontinue the firm for severe enough reductions of $B$.

Proof. See discussion above

\section{A Model with Income Risk}

I introduce in this section a random component in the income of the firm and explore how this risk affects regulation and the choice of capital structure. I consider two income states $\pi_{H}$ and $\pi_{L}$ for the unregulated sector with probabilities $\beta$ and $1-\beta$ such that $\bar{\pi}=\beta \cdot \pi_{H}+(1-\beta) \cdot \pi_{L}$. This income shock is realized after the choice of the regulated quantity (stage 2 in the base model) so both regulator's policy on $q$ and private investment decisions are taken under risk. The decision of the regulator on $q$ implies a choice of the expected return of the investment of the firm. The variance of that return originates from the variability in unregulated income.

These assumptions are reasonable if the regulator can not postpone the decision on $q$ until the unregulated income is determined and it can commit to this decision. In practice, this regulated decision process could be sustained by a restrictive legal regime that limits the possibility to review regulation over time. The new timing is detailed in Figure 2.

A priory, the presence of risk might limit the opportunistic behavior of the regulator, as the incentives to avoid liquidation when unregulated income is low lead to a higher regulated income. However, the possibility of a high realization of unregulated income $\pi_{H}$ also allows 
to limit the support to the firm to that income realization and allow liquidation for low unregulated income $\pi_{L}$. The regulator's policy will depend on the specific characteristics of the regulated and unregulated sectors.

At the end of this section, I consider the possibility of adjusting ex-post the choice of quantity $q$ to the income realization in the unregulated sector. The regulator can then adjust $q$ to avoid both liquidation and excessive transfers to the firm for a given level of debt $D$. However, the managers will know that the regulator has a greater ability to control liquidation and they can increase the leverage of the firm. This lack of commitment can benefit regulators that have a strong preference for continuation of the firm and allow high regulated income when forced to choose $q$ before the realization of unregulated income. I detail next the adaptation of the remaining elements of the basic model:

\section{The Regulator}

The welfare function of the regulator in (1) is unaltered, but the unregulated income of the firm is now random. Consumer surplus from the unregulated sector is also assumed to be random, taking the value $C S_{H}$ with probability $\beta$ and $C S_{L}$ with probability $1-\beta$. There is no strong argument to sign the relation between consumer surplus and income, as variation in unregulated income might correspond to demand, competition and cost shocks. I assume that $C S_{L}<C S_{H}$ to focus the presentation, but this assumption is not essential.

The regulator is willing to invest and allow the continuation of the firm even if low unregulated income $\pi_{L}$ is realized with certainty and the monopoly price is charged:

$$
\alpha \cdot\left(\pi_{L}+\pi\left(q_{m}\right)\right)+C S\left(q_{m}\right)+C S_{L}>\alpha \cdot K>\alpha \cdot L
$$

\section{The Managers and the Investors}

The managers are assumed to continue the operations of the firm even if low unregulated income $\pi_{L}$ is realized and regulated income is set at $q_{r}: \pi_{L}+\pi\left(q_{r}\right)-L+B>0 .{ }^{15}$ External

\footnotetext{
${ }^{15}$ If this assumption is changed, e. g., $\pi_{L}+\pi\left(q_{r}\right)<L-B<\pi_{L}+\pi\left(q_{m}\right)$, the regulator also restricts $q$ when managers are in control. The use of debt implies still higher restrictions in $q$ but the relative distortion and increase in the value of the firm are smaller.
} 
investors are willing to enter liquidation if quantity $q$ is limited to $q_{r}$, so $\pi_{L}+\pi\left(q_{r}\right)-L<0$. I also assume that the income from monopoly in the regulated sector ensures that external investors do not choose liquidation. Hence, I have $\pi_{L}+\pi\left(q_{m}\right)-L>0$.

With regard to the investment decision, I maintain that the managers would be willing to carry out the project at the optimal regulated quantity $q_{r}$ if they had enough cash at hand. That is $\bar{\pi}+\pi\left(q_{r}\right)+B-K>0$.

\subsection{Regulator's Policy}

Given a leveraged firm with debt $D>\pi_{L}+\pi\left(q_{r}\right)$ and an income realization in $\left\{\pi_{L}, \pi_{H}\right\}$, the choice of regulated income $\pi(q)$ determines whether the firm continues in operation. The regulator can choose between supporting the firm at both states $\{H L\}$, only at the high state $\{H\}$ or allowing liquidation at both states $\{\varnothing\}$. The regulatory choice trades off the benefit of ensuring continuation and the cost of inducing a quantity distortion in the regulated sector.

For levels of debt below $L$, avoiding bankruptcy implies a lower quantity distortion than avoiding liquidation and the regulator will choose the former option. The quantities $q_{h}^{D}$ and $q_{l}^{D}$ required to avoid bankruptcy and liquidation for a level of debt $D \leq L$ at each income state are implicitly defined by:

$$
\begin{aligned}
& \pi\left(q_{h}^{D}\right)=\max \left(D-\pi_{H}, \pi\left(q_{r}\right)\right) \\
& \pi\left(q_{l}^{D}\right)=\max \left(D-\pi_{L}, \pi\left(q_{r}\right)\right)
\end{aligned}
$$

The fact that $\pi_{H}>\pi_{L}$ implies that $q_{l}^{D} \leq q_{h}^{D}$ and leads regulated income closer to the monopoly level for an income realization $\pi_{L}$. I apply the implicit function theorem to the constraints in (5) in the range $D>\pi_{H}+\pi\left(q_{r}\right)$ and find that an increase in the debt level $D$ will lead to a higher reduction in $q$ at the low income state $\pi_{L}$ : 


$$
\partial q_{l}^{D} / \partial D=\frac{1}{\pi^{\prime}\left(q_{l}^{D}\right)}<\frac{1}{\pi^{\prime}\left(q_{h}^{D}\right)}=\partial q_{h}^{D} / \partial D<0
$$

from $q_{l}^{D}<q_{h}^{D}$ and the concavity of $\pi(q)$. If debt $D$ is at a low level, $D<\pi_{L}+\pi\left(q_{r}\right)$, marginal increases in $D$ do not affect the probability of liquidation and have no effect on the regulated quantity $q: \partial q_{l}^{D} / \partial D=0$ and $\partial q_{h}^{D} / \partial D=0$. Lemma 3 gathers these considerations:

Lemma 3. The differences in the restricted quantities $\Delta q \equiv q_{h}^{D}-q_{l}^{D}$ and in the marginal effect of an increase in debt $\partial q_{h}^{D} / \partial D-\partial q_{l}^{D} / \partial D$ both increase (at least weakly) with the difference between the two realizations of unregulated income $\Delta \pi \equiv \pi_{H}-\pi_{L}$.

Proof. It follows immediately from (5) that increasing (decreasing) $\pi_{H}\left(\pi_{L}\right)$ leads to a weak increase (decrease) in $q_{h}^{D}\left(q_{l}^{D}\right)$. Concavity of $\pi(q)$ then implies that the difference $\partial q_{h}^{D} / \partial D-\partial q_{l}^{D} / \partial D$ increases (at least weakly)

With this characterization of quantity distortions, I proceed to the analysis of the support policy of the regulator. For debt level $D \leq L$ and quantities $q_{h}^{D}$ and $q_{l}^{D}$ defined by (5), the net gain in the regulator's welfare measure from avoiding bankruptcy and liquidation at the high profit state $\{H\}$ versus allowing liquidation at both states $\{\varnothing\}$ is given by:

$$
\Delta W(H, \varnothing, D) \equiv \beta \cdot\left(\alpha \cdot\left[\pi\left(q_{h}^{D}\right)+\pi_{H}\right]+C S_{H}+C S\left(q_{h}^{D}\right)-\alpha \cdot L\right)
$$

that is equal to the additional welfare from continuation at the high income state $\pi_{H}$. There is no difference in welfare at the low income state $\pi_{L}$ as the firm is liquidated under both $\{H\}$ and $\{\varnothing\}$. For $D \leq L$, the quantity $q_{h}^{D}$ is above monopoly level $q_{m}$, and it is immediate that the regulator prefers continuation by the assumption in (4).

The net effect in the regulator's welfare measure of avoiding bankruptcy and liquidation at both states $\{H L\}$ versus limiting support only to the state with high income $\{H\}$ can not be signed so easily. This difference is given by the expression: 


$$
\begin{aligned}
\Delta W(H L, H, D) \equiv & (1-\beta) \cdot\left(\alpha \cdot\left(\pi_{L}+\pi\left(q_{l}^{\nu}\right)-L\right)+C S\left(q_{l}^{\nu}\right)+C S_{L}\right) \\
& -\beta \cdot\left(\alpha \cdot \pi\left(q_{h}^{D}\right)+C S\left(q_{h}^{D}\right)-\alpha \cdot \pi\left(q_{l}^{D}\right)-C S\left(q_{l}^{D}\right)\right)
\end{aligned}
$$

The first term in (7) is equal to the additional regulator's welfare from continuation at the low income state $\pi_{L}$. As the debt level $D$ increases, this term unequivocally decreases, as the regulator's support of the firm at the state $\pi_{L}$ requires a greater quantity distortion. The second term in (7) represents the welfare loss at state $\pi_{H}$ from choosing $q_{l}^{D}$ rather than $q_{h}^{D}$, and it also decreases as the debt level $D$ increases. This follows from the next two observations: (a) the marginal quantity variation $\partial q_{l}^{D} / \partial D$ at state $\pi_{L}$ is smaller (more negative) than $\partial q_{h}^{D} / \partial D$ by Lemma 3 and (b) the function $\alpha \cdot \pi(q)+C S(q)$ is concave and its first derivative increases as $q$ is reduced below $q_{r}$. Consequently,

$$
\partial\left[\alpha \cdot \pi\left(q_{h}^{D}\right)+C S\left(q_{h}^{D}\right)\right] / \partial q_{h}^{D} \cdot \partial q_{h}^{D} / \partial D-\partial\left[\alpha \cdot \pi\left(q_{l}^{D}\right)+C S\left(q_{l}^{D}\right)\right] / \partial q_{l}^{D} \cdot \partial q_{l}^{D} / \partial D>0
$$

As the debt level increases, (7) declines monotonically and there exists a maximum debt level $D^{\text {crit }} \leq L$ such that the regulator prefers (at least weakly) the policy $\{H L\}$ over $\{H\}$, i.e., $\Delta W\left(H L, H, D^{\text {crit }}\right) \geq 0$, if and only if $D \leq D^{\text {crit }}$. I can then define the maximum feasible debt level $D^{*}$ that avoids the regulator's switch from policy $\{H L\}$ to $\{H\}$ as: ${ }^{16}$

$$
D^{*}=\max \left(0, D^{\text {crit }}\right)
$$

The optimal policy of the regulator is to support the firm at both income states $\{H L\}$ if $D \leq D^{*}$ and limit support to the high income state $\{H\}$ if $D>D^{*}$. Given the monotonicity of $\Delta W(H L, H, D)$, the evaluation of $(7)$ at $L$ is enough to determine whether $D^{*}<L$. If $\Delta W(H L, H, L) \geq 0$, then there is no $D^{\text {crit }}<L$ such that $\Delta W\left(H L, H, D^{\text {crit }}\right) \leq 0$ and

\footnotetext{
${ }^{16}$ The critical level $D^{*}$ can be zero if the regulator has preference for expropriation with $\pi\left(q_{r}\right)+\pi_{L}<0$. It is not possible to issue a negative amount of debt and $D=0$ can be above $\pi\left(q_{r}\right)+\pi_{L}$ and $D^{\text {crit }}$.
} 
$D^{*}=\max (0, L)=L$. On the contrary, $\Delta W(H L, H, L)<0$, implies that critical level $D^{\text {crit }}$ is below $L$ and $D^{*}<L$. The maximum feasible debt level remains $L$ as the regulator still needs to avoid liquidation rather than bankruptcy to ensure the continuation at a given income state $\pi_{L}$ or $\pi_{H}$.

The critical level $D^{*}$ is specific to the regulatory environment and it is an implicit function of all the parameters of the model. The following lemma summarizes some comparative statics:

Lemma 4. For a given liquidation value $L, D^{*}$ is (at least weakly):

(i) decreasing in the high income state $\pi_{H}$.

(ii) increasing in the low income state $\pi_{L}$.

(iii) decreasing in a spread $\Delta \pi \equiv \pi_{H}-\pi_{L}$ over the level of income $\pi$ such that $\pi_{L}<\pi<$ $\pi_{H}$ and the reduction of $D^{*}$ from taking such spread is higher than the one resulting from a deterioration of profits $\Delta \pi \equiv \pi-\pi_{L}$ for $\pi_{L}<\pi<\pi_{H}$.

(iv) decreasing in the probability of the high income state $\beta$.

(v) increasing in the regulator's weight $\alpha$ if $D^{*} \rightarrow L$.

(vi) increasing in the consumer surplus in the low income state $C S_{L}$.

Proof. See the Appendix B for a detailed proof

\subsection{The Capital Structure and Value of the Firm}

I focus on the use of debt under the bankruptcy process oriented to liquidation. Reorganization relaxes the income constraints at every income state in line with the results in Proposition 2 and the financing capacity associated to non-voting equity is not affected by the introduction of income risk. If managers issue non-voting equity, the regulator anticipates that they will keep control of the liquidation decision at both income states. The regulator will have no incentives to distort $q$ and increase regulated income. Risk neutral investors will anticipate a maximum payment $\bar{\pi}+\pi\left(q_{r}\right)$ and they will not contribute equity financing above this amount. The logic of Section 3.1 remains valid. 
The value of debt is however altered by the presence of risk. For example, given a critical value $D^{*}=L$, the regulator guarantees continuation of the firm at the income state $\pi_{L}$ even if the debt of the firm is as high as $L$. The managers have no incentive to choose $D<L$ and the value of the firm for $D=L$ increases with respect to the scenario with no risk by the expected excess regulated income $\beta \cdot \Delta \pi$ in the high income state. I will use for the rest of the section the notation $V_{H L}, D$ and $V_{H, D}$ to denote the value of the firm for managers if continuation is allowed at both states $\left\{\pi_{L}, \pi_{H}\right\}$ or only at the high income state $\pi_{H}$ and firm's debt is $D$. For $D=D^{*}=L$, the value of the firm is then:

$$
V_{H L, L}=\bar{\pi}+\pi\left(q_{l}^{L}\right)+B-K
$$

where $\pi\left(q_{l}^{L}\right)=L-\pi_{L}>L-\bar{\pi}$. With respect to the scenario with no risk, the change in the value of the firm is $\bar{\pi}+\pi\left(q_{l}^{L}\right)-L=\beta \cdot \Delta \pi$, as stated above. The rest of the section studies the managers's optimal choice of debt level and the firm's value.

\section{Optimal Level of Debt}

I characterize first the evolution of the value of the firm as a function of debt for $D^{*}<L$. I assume throughout that the managers have enough cash to fund the project in combination with debt $D$, i. e., $D+A \geq K$. I turn back to the relation between the choice of the level of debt and the capital needs $S \equiv K-A$ at the end of the section.

(a) For debt level $D$ such that $0 \leq \pi_{L}+\pi\left(q_{r}\right)<D \leq D^{*}$, the value of the firm is:

$$
\beta \cdot\left(\pi_{H}+\pi\left(q_{l}^{D}\right)-D+B\right)+(1-\beta) \cdot\left(\pi_{L}+\pi\left(q_{l}^{D}\right)-D+B\right)-(K-D)
$$

or, more compactly,

$$
V_{H L, D}=\beta \cdot(\Delta \pi)+D+B-K
$$

The value $V_{H L, D}$ increases with $D$ as the regulator restricts $q$ to avoid liquidation at income state $\pi_{L}$. For $D \leq \pi_{L}+\pi\left(q_{r}\right)$, debt and non-voting equity are equivalent instruments. 
Managers can achieve the full equity value with no risk $\bar{\pi}+\pi\left(q_{r}\right)+B-K$ by issuing debt $D \simeq \pi_{L}+\pi\left(q_{r}\right)<\bar{\pi}+\pi\left(q_{r}\right)$. An equity issue of size $E$ such that $\pi_{L}+\pi\left(q_{r}\right)<E \leq \bar{\pi}+\pi\left(q_{r}\right)$ leads to a smaller increase in the value of the firm than an issue of debt of the same size.

(b) At debt level $D$ such that $0 \leq \pi_{L}+\pi\left(q_{r}\right)<D^{*}<D=D^{*}+\epsilon$, for $\epsilon \rightarrow 0$, there is a discontinuous decline in the value of the firm, as the regulator stops supporting the continuation of the firm at the low income state $\pi_{L}$. For $D^{*}>0$, the reduction in the value of the firm for a change from $D^{*}$ to $D^{*}+\epsilon$ is:

$$
\beta \cdot(\Delta \pi)+(1-\beta) \cdot\left(\pi\left(q_{l}^{D^{*}}\right)+\pi_{L}+B-L\right)
$$

This expression includes the expected excess income $\beta \cdot(\Delta \pi)$ earned at the high income state $\pi_{H}$ for $D \leq D^{*}$ and the managers's loss from liquidation at the low income state $\pi_{L}$. Managers have therefore no incentive to increment debt marginally over $D^{*}$.

(c) For values of debt $D$ such that $0 \leq \pi_{L}+\pi\left(q_{r}\right)<D^{*}<D<L$, the value of the firm increases as the regulator is forced to restrict quantity $q$ to sustain the firm at the high income state $\pi_{H}$. The value of the firm is now:

$$
V_{H, D}=\beta \cdot(D+B)+(1-\beta) \cdot L-K
$$

The managers prefer $L$ over any level of debt in the interval $\left(D^{*}, L\right): V_{H, L}>V_{H, D}$ for all $D>D^{*}$. If $D^{*}<L$, the continuous choice over $D$ is simplified into a discrete choice between critical levels $D^{*}$, for a value of the firm $V_{H L, D^{*}}$, and $L$, for a value of the firm $V_{H, L}$. For $D^{*}=L$, the managers simply choose $D=D^{*}=L$ and collect firm's value $V_{H L, L}$.

(d) If $D^{*}=0$, any positive level of debt will lead the regulator to support the firm exclusively at the income state $\pi_{H}$. The value of the firm at $D=D^{*}=0$, which implies full equity financing, is then:

$$
V_{H L, 0}=\bar{\pi}+\pi\left(q_{r}\right)+B-K
$$


For a debt level $D=D^{*}+\epsilon>D^{*}=0$, for $\epsilon \rightarrow 0$, there is again a discontinuous change in the value of the firm, which is given in this case by:

$$
\beta \cdot \max \left(\epsilon-\pi\left(q_{r}\right)-\pi_{H}, 0\right)+(1-\beta) \cdot\left(\pi\left(q_{r}\right)+\pi_{L}+B-L\right)
$$

where the first term might be positive as result of avoiding a possibly negative income $\pi\left(q_{r}\right)+\pi_{H}$ at income state $\pi_{H}$. However, it is still the case that $V_{H, L}>V_{H, D}$ for all $D>D^{*}$, as the only marginal effect of increasing the debt level above $D^{*}=0$ is to force higher regulated income at state $\pi_{H}$.

\section{Valuation Impact of Income Risk}

I will compare the optimal value of the firm in this section with the value with no risk, $V_{L} \equiv L+B-K$. The case $D^{*}=L$ was already described at the beginning of the section. For $D^{*}<L$, the following value comparisons hold:

(a) The value of the firm at full leverage decreases with the introduction of income risk. The possibility of liquidation at the low income state $\pi_{L}$ imposes the loss of private benefits $B$ in this event. Formally,

$$
V_{L}-V_{H, L}=(L+B-K)-(L+\beta \cdot B-K)=(1-\beta) \cdot B>0
$$

(b) The difference in value of the firm with leverage $D^{*}$ in the scenario with income risk, $V_{H L, D^{*}}$, compared with the value of the firm in the scenario with no risk, $V_{L}$, is:

$$
V_{L}-V_{H L, D^{*}}=(L+B-K)-\left(D^{*}+B+\beta \cdot \Delta \pi-K\right)
$$

This expression is positive if and only if the expected excess income $\beta \cdot \Delta \pi$ is not high relative to the reduction in the debt level from $L$ to $D^{*}$. That is, $D^{*}<L-\beta \cdot \Delta \pi$. 
(c) In the scenario with risk, the sign of the difference $V_{H, L}-V_{H L, D^{*}}$ will again depend on the relative size of the critical level of debt $D^{*}$. I calculate the difference:

$$
\begin{aligned}
V_{H, L}-V_{H L, D^{*}} & =(L+\beta \cdot B-K)-\left(D^{*}+B+\beta \cdot \Delta \pi-K\right) \\
& =L-\left(D^{*}+(1-\beta) \cdot B+\beta \cdot \Delta \pi\right)
\end{aligned}
$$

that implies that $V_{H, L}-V_{H L, D^{*}}>0$ if and only if $D^{*}<L-(1-\beta) \cdot B-\beta \cdot \Delta \pi$. The managers are better off constraining debt $D$ to $D^{*}$ if the difference $L-D^{*}$ is not big relative to the benefits of excess income $\beta \cdot \Delta \pi$ and protection of private benefits $(1-\beta) \cdot B$ for $D=D^{*}$.

(d) In case that $D^{*}=0$, the above value comparisons must be computed using (9) to obtain $V_{H L, D^{*}}=V_{H L, 0}$. Then, I have that:

$$
\begin{aligned}
V_{H, L}-V_{H L, 0} & =(L+\beta \cdot B-K)-\left(\bar{\pi}+\pi\left(q_{r}\right)+B-K\right) \\
& =L-\bar{\pi}-\pi\left(q_{r}\right)-(1-\beta) \cdot B \\
V_{L}-V_{H L, 0} & =(L+B-K)-\left(\bar{\pi}+\pi\left(q_{r}\right)+B-K\right) \\
& =L-\bar{\pi}-\pi\left(q_{r}\right)>0
\end{aligned}
$$

The managers that limit debt to $D^{*}=0$ are worse off than in the scenario with no risk, as $V_{L}-V_{H L, 0}>0$, but they might still choose to limit leverage to zero if the private benefits are high enough so $V_{H, L}-V_{H L, 0}<0$ and the financing needs can be covered with internal funds or non-voting equity.

The common lesson of the different value comparisons is that the managers will benefit from the introduction of risk if the critical debt level $D^{*}$ is sufficiently high. I summarize the results in the following proposition: ${ }^{17}$

Proposition 3. The introduction of a spread $\Delta \pi$ in unregulated income leads to the following capital structure choices and value of the firm if managers can freely choose the level of leverage. For $D^{*}>\pi\left(q_{r}\right)+\pi_{L}>0$, the value comparison yields:

\footnotetext{
${ }^{17}$ The cases in Proposition 3 correspond to different sets of non-linear conditions on the parameters of the model, as $D^{*}$ and the bounds are a function of these parameters. The different cases are exclusive.
} 
(i) The optimal amount of leverage equals $L$ to attain a value $V_{H, L}$ if and only if $D^{*}<$ $L-(1-\beta) \cdot B-\beta \cdot \Delta \pi$. This implies a reduction in firm's value with respect to the scenario with no risk as $V_{H, L}<V_{L}$.

(ii) The optimal amount of leverage equals $D^{*}$ to attain a value $V_{H L, D^{*}}<V_{L}$ if and only if $L-(1-\beta) \cdot B-\beta \cdot \Delta \pi \leq D^{*}<L-\beta \cdot \Delta \pi$.

(iii) The optimal amount of leverage equals $D^{*}$ to attain a value $V_{H L, D^{*}} \geq V_{L}$ if and only if $L-\beta \cdot \Delta \pi \leq D^{*}<L$.

(iv) The optimal amount of leverage equals $L$ to attain a value $V_{H L, L}>V_{L}$ if and only if $L=D^{*}$.

For $D^{*}=0>\pi\left(q_{r}\right)+\pi_{L}$, the value comparison yields:

(v) The optimal amount of leverage equals $D^{*}=0$ to attain a value $V_{H L, 0}<V_{L}$ if and only if $L-\bar{\pi}-\pi\left(q_{r}\right) \leq(1-\beta) \cdot B$.

(vi) The optimal amount of leverage equals $L$ to obtain $V_{H, L}<V_{L}$ if and only if $L-\bar{\pi}-$ $\pi\left(q_{r}\right)>(1-\beta) \cdot B$.

Proof. See discussion above

The case (iii) is illustrated graphically in Figure 3. This case is interesting as income risk forces the managers to limit debt below liquidation value $L$, but still $V_{H L, D^{*}} \geq V_{L}$ as average regulated income is kept at a level high enough to avoid liquidation at income state $\pi_{L}$. Figure 4 illustrates the case (ii), where the reduction from $L$ to $D^{*}$ is high enough to have $V_{H L, D^{*}}<V_{L}$.

The managers will not be able to attain the optimal value $V_{H L, D^{*}}$ in cases (ii) and (iii) if financing constraints are severe enough: $D^{*}<S<L$. The managers might want to limit the issuance of debt to $D^{*}$ to avoid the risk of losing private benefits $B$, but they might lack the cash to cover the gap between $D^{*}$ and $S \equiv K-A$. The introduction of a spread $\Delta \pi$ does not alter the maximum funding capacity equal to $L$ and the presence of cash needs superior to $D^{*}$ can lead to the choice of a capital structure with $D=L$ that is suboptimal from the perspective of the managers. Alternatively, it is possible that $S<D^{*} \leq L$ and, as in the 
case with no risk in Section 3, the managers will choose to fund the project with excessive debt, $D=D^{*}>S$, in order to retain a higher fraction of their own cash reserves $A$.

The use of voting-equity still forces the regulator to set regulated income at a level such that the verifiable continuation value exceeds the liquidation value $L$. This form of security is then equivalent to the issuance of an amount of debt $L$. The managers will avoid the use of voting equity in favor of a limited issuance of debt $D^{*}$ if $V_{H L, D^{*}} \geq V_{H L, L}$ and they have enough internal funds.

The specific case of Proposition 3 that holds in an industry depends on the combination of all the parameters describing the market and firm conditions. However, it is possible to find some simple relations for some parameters. As $B \rightarrow \infty$, the scenarios (i) and (vi) in Proposition 3 are ruled out. The value of private benefits is too high for managers to allow a positive probability of liquidation. If $C S_{L} \rightarrow \infty, D^{*} \rightarrow L$ and the scenario (iv) in Proposition 3 must hold. The regulator is forced to increase average regulated income to avoid a high loss of consumer surplus. In general, numerical analysis is required to find the optimal capital structure and regulatory policy in a given industry. Appendix C presents a simple example with linear demand and quadratic costs.

\subsection{No Commitment}

I modify here the assumptions in the previous parts of Section 4 to allow the regulator and the firm to adjust the quantity $q$ after the income shock is realized. Given an income realization in $\left\{\pi_{L}, \pi_{H}\right\}$, the regulator will face the same problem as in Section 3. For a given realization in $\left\{\pi_{L}, \pi_{H}\right\}$, it is then possible to adjust regulated income to cover exactly the difference between debt payments $D$ and unregulated income. There is no longer need to allow excess regulated income at the high income state $\pi_{H}$.

The managers will anticipate the perfect control of the regulator over the events of bankruptcy and liquidation. Managers will also anticipate that the regulator will not increase allowed regulated income unless the capital structure of the firm creates a real threat of 
liquidation. The incentives of managers to increase debt up to liquidation value $L$ stay then constant with respect to the scenario with no risk in Section 3 and firm's value equals $V_{L}=L+B-K$.

Lemma 5. If the regulator can not commit to a particular policy on $q$ before the income realization in $\left\{\pi_{L}, \pi_{H}\right\}$ is known, the equilibrium capital structure, firm's value and regulatory policy are determined by application of the model with no risk in sections 2 and 3.

Proof. See discussion above

Proposition 3 allows to evaluate the change in firm's value when the regulatory regime with commitment is abandoned, as this firm's value is guaranteed to equal $V_{L}$ under no commitment. The switch to the regime with no commitment hurts the managers if they are able to maintain high leverage under commitment and still ensure the continuation of the firm in both income states, as in cases (iii) and (iv) in Proposition 3.

Lack of commitment allows the regulator to ensure the continuation of the firm and matches regulated income to financial needs exactly. The cost for the regulator of the flexibility that comes with the lack of commitment is that managers will increase the leverage of the firm. The magnitude of this cost will be small if the critical value $D^{*}$ under the commitment regime is close to $L$. I analyze next these welfare changes in more detail.

\section{Welfare Implications}

I compare here the welfare measure of the regulator when it can commit to a quantity $q$ at $t=2$, and when it is able to adjust $q$ after the income realization at $t=3$. The expected welfare measure of a regulator that can not commit is:

$$
\begin{aligned}
W_{N C}= & \beta \cdot\left(\alpha \cdot\left(\pi\left(q_{h}^{L}\right)+\pi_{H}-K\right)+C S_{H}+C S\left(q_{h}^{L}\right)\right) \\
& +(1-\beta) \cdot\left(\alpha \cdot\left(\pi\left(q_{l}^{L}\right)+\pi_{L}-K\right)+C S_{L}+C S\left(q_{l}^{L}\right)\right)
\end{aligned}
$$

or, more conveniently,

$$
W_{N C}=\beta \cdot W_{H}\left(q_{h}^{L}\right)+(1-\beta) \cdot W_{L}\left(q_{l}^{L}\right)
$$


where $W_{H}($.$) and W_{L}($.$) are increasing functions of q$ in $\left[q_{m}, q_{r}\right]$ and adopt the form in (1) for given consumer surplus and income realizations in $\left\{C S_{L}, C S_{H}\right\}$ and $\left\{\pi_{L}, \pi_{H}\right\}$. The quantity levels $q_{h}^{L}$ and $q_{l}^{L}$ solve the system in (5) for $D=L$, as the mangers choose maximum leverage when the regulator can not commit. I use the notation $W_{H L, D}$ and $W_{H, D}$ to denote the welfare measure of the regulator if commitment is possible, continuation is allowed at states $\{H L\}$ and $\{H\}$ and debt is $D$.

Absence of commitment is optimal for the regulator if the managers would choose a very high level of debt even if the regulator can commit ex ante. If managers choose $D=D^{*}=L$ when the regulator has commitment power, the welfare comparison yields:

$$
W_{N C}-W_{H L, L}=\beta \cdot\left(W_{H}\left(q_{h}^{L}\right)-W_{H}\left(q_{l}^{L}\right)\right)>0
$$

from the fact that $W_{H}($.$) is increasing in q$ and $q_{h}^{L}>q_{l}^{L}$. In this case, lack of commitment allows the regulator to support the continuation of the firm at income state $\pi_{H}$ with a smaller quantity distortion. If managers choose $D=L>D^{*}$ :

$$
W_{N C}-W_{H, L}=(1-\beta) \cdot\left(W_{L}\left(q_{l}^{L}\right)-\alpha \cdot(L-K)\right) \geq 0
$$

from the assumption that $\alpha \cdot\left(\pi(q)+\pi_{L}\right)+C S_{L}+C S(q)-\alpha \cdot L>0$ for $q \in\left[q_{m}, q_{r}\right]$.

Commitment can benefit the regulator if it reduces the strategic use of debt by managers to a level $D=D^{*}<L$ that is sufficiently low. The welfare criterion to evaluate the two regimes is:

$$
\begin{aligned}
W_{N C}-W_{H L, D^{*}}= & \beta \cdot\left(W_{H}\left(q_{h}^{L}\right)-W_{H}\left(q_{l}^{D^{*}}\right)\right) \\
& +(1-\beta) \cdot\left(W_{L}\left(q_{l}^{L}\right)-W_{L}\left(q_{l}^{D^{*}}\right)\right)
\end{aligned}
$$

Lack of commitment restricts quantity $q$ at state $\pi_{L}$ and the second term in the above expression is clearly negative from the fact that $W_{L}($.$) is increasing in \left[q_{m}, q_{r}\right]$ and $q_{l}^{L}<q_{l}^{D^{*}}$ 
from (5) and $D^{*}<L$. If the first term is non-positive, commitment would be immediately optimal in this case. Monotonicity of $W_{H}($.$) implies that W_{H}\left(q_{h}^{L}\right)-W_{H}\left(q_{l}^{D^{*}}\right)<0$ if and only if $q_{h}^{L}<q_{l}^{D^{*}}:$

(a) If $D^{*}$ allows the regulator to set $q_{l}^{D^{*}}=q_{r} \geq q_{h}^{L}, W_{H}\left(q_{h}^{L}\right)-W_{H}\left(q_{l}^{D^{*}}\right) \leq 0$ and the regulator benefits from commitment. In particular, commitment allows a pro-liquidation regulator with $D^{*}=0$ to prevent the strategic use of leverage by managers with high private benefits, as in case (v) in Proposition 3.

(b) If $D^{*}$ constrains the regulator to set $q_{l}^{D^{*}}<q_{r}, W_{H}\left(q_{h}^{L}\right)-W_{H}\left(q_{l}^{D^{*}}\right)<0$ if and only if $D^{*}<L-\Delta \pi$, which is not necessary for $D^{*}<L .{ }^{18}$ A positive term $W_{H}\left(q_{h}^{L}\right)-W_{H}\left(q_{l}^{D^{*}}\right)$ implies that the risk of liquidating the firm in the low income state induces a higher distortion in $q_{l}^{D^{*}}$ than the one required in $q_{h}^{L}$ to avoid certain liquidation at income state $\pi_{H}$. This positive term can induce the regulator to prefer absence of commitment for a high enough level of critical debt $D^{*}$, as shown in Proposition 4 below. For a particular industry, numerical analysis allows to measure whether $D^{*}$ is sufficiently high. I summarize the results in the following proposition:

Proposition 4. Regulatory commitment to a quantity level $q$ at $t=2$ produces a loss in the regulator's welfare measure with respect to the no commitment policy if it induces managers to choose $D>\bar{D}$ where $\bar{D} \in(L-\Delta \pi, L)$. Conversely, regulatory commitment generates a positive variation in the regulator's welfare if it induces managers to choose $D=D^{*} \leq \bar{D}$. In particular,

(i) If managers choose $D=L=D^{*}$ or $D=L>D^{*}$, commitment is not optimal.

(ii) If managers choose full equity funding, $D=0=D^{*}$, commitment is optimal and allows the regulator to set its preferred quantity level $q^{r}$.

Proof. The extreme cases in (i) and (ii) have been proved above. To show the existence of $\bar{D}$, I take into account that $W_{N C}-W_{H L, D^{*}}<0$ for a critical debt level $D^{*} \leq L-\Delta \pi$ and

\footnotetext{
${ }^{18}$ This follows from taking the difference of $\pi_{H}+\pi\left(q_{h}^{L}\right)=L$ and $\pi_{L}+\pi\left(q_{l}^{D^{*}}\right)=D^{*}$ which leads to $\pi\left(q_{h}^{L}\right)-$ $\pi\left(q_{l}^{D^{*}}\right)=L-\Delta \pi-D^{*}$. The fact that $\pi($.$) is decreasing in q$ in the relevant range leads to $q_{h}^{L}<q_{l}^{D^{*}} \longleftrightarrow$ $D^{*}<L-\Delta \pi$.
} 
$W_{N C}-W_{H L, D^{*}}>0$ for $D^{*}=L$. The expression $W_{N C}-W_{H L, D^{*}}$ in (11) can be rewritten as:

$$
\begin{aligned}
W_{N C}-W_{H L, D^{*}}= & \beta \cdot\left(w\left(q_{h}^{L}\right)-w\left(q_{l}^{D^{*}}\right)\right) \\
& +(1-\beta) \cdot\left(w\left(q_{l}^{L}\right)-w\left(q_{l}^{D^{*}}\right)\right)
\end{aligned}
$$

where $w(q)=\alpha \cdot \pi(q)+C S(q)$ is continuous in $q$. The equations in (5) and continuity of $\pi($.$) imply that quantity level q_{l}^{D^{*}}$ is a continuous function of a hypothetical critical value $\widehat{D}=D^{*}$. Function (12) is thus continuous in $\widehat{D}=D^{*}$, and the intermediate value theorem guarantees the existence of a set of critical values $\widehat{D} \in(L-\Delta \pi, L)$ such that (12) is equal to zero. The differentiability assumptions in Section 2 allow me to apply the chain rule to $\partial\left(W_{N C}-W_{H L, D^{*}}\right) / \partial D^{*}$ and obtain:

$$
\partial\left(W_{N C}-W_{H L, D^{*}}\right) / \partial D^{*}=\partial q_{(-)}^{D^{*}} / \partial D^{*} \cdot \partial \underset{(+)}{w\left(q_{l}^{D^{*}}\right) / \partial q \cdot(-\beta-(1-\beta))>0}
$$

where the sign of $\partial q_{l}^{D^{*}} / \partial D^{*}$ is derived from (6). Function (12) is then monotone increasing in the hypothetical debt value $\widehat{D}=D^{*}$ and there is a single $\bar{D}$ such that (12) is equal to zero, as stated $\mathbf{\square} .^{19}$

Finally, I point out that the regulator downweights the income of the firm, and the change in total social welfare can diverge from the variation in the regulator's measure of welfare. If $q_{s o c} \equiv \arg \max \pi(q)+C S(q)$ and, given that $q_{m}<q_{s o c} \leq q_{r}$, the switch to a commitment regime that allows to expand quantity $q$ from $q_{h}^{L}<q_{\text {soc }}$ and $q_{l}^{L}<q_{\text {soc }}$ towards $q_{l}^{D^{*}}>q_{\text {soc }}$ has ambiguous consequences in total welfare as it substitutes a monopolistic quantity distortion with excessive provision of $q$. Hypothetically, if commitment allows the expansion of quantity $q$ from $q_{h}^{L} \geq q_{s o c}$ and $q_{l}^{L} \geq q_{s o c}$ towards $q_{l}^{D^{*}}>q_{s o c}$, it would actually decrease social welfare, as it allows greater excess in $q$. If quantity $q$ is expanded from $q_{h}^{L}<q_{\text {soc }}$ and $q_{l}^{L}<q_{\text {soc }}$ towards $q_{l}^{D^{*}} \leq q_{s o c}$, commitment increases social welfare as it allows a lower monopolistic

\footnotetext{
${ }^{19}$ This proof shows that commitment creates value if managers choose debt $D=D^{*}$ that is below $\bar{D}$ for a given set of the model's parameters. Comparative statics on the variation of the model parameters would require a different calculation as $D^{*}, \bar{D}$ and (12) are functions of the parameters.
} 
distortion. The variation of the regulator's welfare measure and social welfare as a function of the ability of the regulator to commit will be aligned in this latter case.

\section{Conclusion}

I provide in this article a framework in which the conflicts of interest between the different stakeholders (managers, external investors, regulator) of a regulated firm make the welfare of consumers and the value of this firm a function of its capital structure. A bankruptcy procedure with voluntary initiation is introduced to study the firm's choice of capital structure and regulatory policy, and I find that the true strategic value of the capital structure depends on specific characteristics of bankruptcy law and the ability of the regulator to commit to a limit on regulated income.

The analysis reveals that it is plausible that the managers of the regulated firm threaten the regulator with the transfer of control to external investors to force higher regulated income. This strategy is based on the relative higher value that the managers and the regulator attach to continuation versus the external investors. The present work shows how the transfer of control to investors becomes less of a threat to the regulator if the incentives of the external investors for continuation improve. In this line, if bankruptcy regulation allows for favorable conditions for reorganization versus liquidation, the use of leverage imposes fewer constraints on the regulator. On the contrary, a relatively high liquidation value can lead to a positive relation between leverage and regulated income. I also find that the transfer of control to external shareholders through the issue of new voting equity can replicate the strategic effect of high leverage if the new shareholders can not appropriate the private benefits of managers. A pro-liquidation bankruptcy regime or the possibility to transfer control with the issuance of new voting equity will then provide the regulator with incentives to limit the discretion of the regulated firm to choose its capital structure. 
The results of the article predict that a pro-liquidation framework will protect beneficial investments in industries where firms have a high need of external finance, the liquidation value of the firms's assets is aligned with financing needs and the regulator has a pro-consumer bias. In these industries, the regulators would have an incentive to hold up investors if the threat of liquidation through the bankruptcy process is not present. If the above conditions do not hold, the conclusions must be revised. Firms with high retained earnings might abuse the recourse to the liquidation process to force favorable regulation. For example, utility firms might distribute high dividends and then finance the implementation of new technology with uncertain cost with debt, and commercial banks might also choose to pay high dividends during lending booms rather than using retained earnings to finance a higher proportion of their loans. If the firm's bankruptcy costs are high and the liquidation value of the firms's assets is low, as it might be the case with part of the infrastructure of some utilities, the pro-liquidation framework does not impose a strong constraint on the regulator. Additionally, a regulator with incentives aligned with the firm rather than with consumers offers no justification for leverage as an investor protection scheme.

The policy of committing to a particular level of regulated income rather than adjusting income ex post to exogenous shocks is also studied and it is found that optimal policy will depend on the characteristics of the market. Commitment is not an unequivocally superior policy. It might help to improve the regulator's welfare measure if the regulator's continuation value is low relative to the continuation value of managers. In this case, commitment to a relatively low regulated income forces the managers to limit leverage and the regulator can increase consumer surplus without increasing the risk of liquidation. However, sufficient conditions, particularly a high continuation value for the regulator, also exist for this commitment power to force the regulator to ensure continuation of the firm at a social cost higher than with the ex post optimal policy. 


\section{A Sufficient Conditions for Concavity}

Concavity of $\pi(q)$ and $W(q)$ is guaranteed if $\pi^{\prime \prime}(q)<0$ and $W^{\prime \prime}(q)<0$, which are well defined conditions given that $\pi(q)$ and $W(q)$ are $C^{2}$ functions. If I define regulated revenues as $R(q)$, it is easy to combine $\pi^{\prime \prime}(q)<0$ and $W^{\prime \prime}(q)<0$ into:

$$
\frac{p^{\prime}(q)-\alpha \cdot C^{\prime \prime}(q)}{(1-\alpha)}<R^{\prime \prime}(q)<C^{\prime \prime}(q)
$$

The right and left bounds correspond respectively to the conditions $\pi^{\prime \prime}(q)<0$ and $W^{\prime \prime}(q)<0$. The revenue function $R(q)$ should not be too convex to keep $\pi(q)$ a concave function. However, $R(q)$ is subtracted from gross consumer surplus and enters $W(q)$ with negative sign, so $R(q)$ should not be too concave to keep $W(q)$ a concave function. Expanding the second derivative of revenues, $R^{\prime \prime}(q)=p^{\prime \prime}(q) \cdot q+2 \cdot p^{\prime}(q)$, I rewrite (13) as the condition (2) given in Section 2:

$$
\frac{(2 \cdot \alpha-1) \cdot p^{\prime}(q)-\alpha \cdot C^{\prime \prime}(q)}{(1-\alpha)}<p^{\prime \prime}(q) \cdot q<C^{\prime \prime}(q)-2 \cdot p^{\prime}(q)
$$

Given the assumption that $p^{\prime}(q)<0$ and $C^{\prime \prime}(q) \geq 0$ in Section 2, this extra condition only restricts $p^{\prime \prime}(q)$. These bounds are properly defined if the right hand bound exceeds the value of the left hand bound. That is,

$$
\begin{aligned}
(2 \cdot \alpha-1) \cdot p^{\prime}(q)-\alpha \cdot C^{\prime \prime}(q) & <(1-\alpha) \cdot C^{\prime \prime}(q)-2 \cdot(1-\alpha) \cdot p^{\prime}(q) \\
& \Leftrightarrow p^{\prime}(q)<C^{\prime \prime}(q)
\end{aligned}
$$

which holds by the assumption that $p^{\prime}(q)<0$ and $C^{\prime \prime}(q) \geq 0$. 


\section{B Proof of Lemma 4}

In this appendix, I will use the notation $\partial \Delta W / \partial x$ to refer to the derivative of the function $\Delta W\left(H L, H, D^{*}\right)$ with respect to a given parameter $x$. The function $\phi($.$) will refer to the$ inverse function of the regulated income $\pi($.$) . Given the relevant range \left[q_{m}, q_{r}\right], \phi($.$) is a$ one-to-one, strictly decreasing and concave function. ${ }^{20}$ Additionally, I use $w(q)$ to denote the term $\alpha \cdot \pi(q)+C S(q)$. Given the relevant range $\left[q_{m}, q_{r}\right], w(q)$ is a one-to-one, strictly increasing and concave function from assumptions in Section 2.

For a critical level of debt $D^{*}$, the net welfare difference between the policies $\{H\}$ and $\{H L\}$ is zero at $D=D^{*}$. Using the expression in (7):

$$
\Delta W\left(H L, H, D^{*}\right)=0
$$

The implicit function theorem, IFT henceforth, can be applied to (14), to obtain $\partial D^{*} / \partial x=$ $-(\partial \Delta W / \partial x) /\left(\partial \Delta W / \partial D^{*}\right)$ for $D^{*} \in(0, L)$ and parameter of interest $x$. If $D^{*}=0$ and $D^{\text {crit }}<D^{*}$ or $D^{*}=L,(14)$ does not generally hold and $D^{*}$ is constant in marginal variations of the parameters: $\partial D^{*} / \partial x=0$. That is why I include the qualification "at least weakly" in Lemma $4 .{ }^{21}$ I next calculate $\partial \Delta W / \partial D^{*}$ :

$$
\begin{aligned}
\frac{\partial \Delta W}{\partial D^{*}}= & (1-\beta) \cdot\left(\frac{\partial w\left(\phi\left(D^{*}-\pi_{L}\right)\right)}{\partial \phi(.)} \cdot \frac{\partial \phi\left(D^{*}-\pi_{L}\right)}{\partial D^{*}}\right) \\
& -\beta \cdot\left(\frac{\partial w\left(\phi\left(D^{*}-\pi_{H}\right)\right)}{\partial \phi(.)} \cdot \frac{\partial \phi\left(D^{*}-\pi_{H}\right)}{\partial D_{(-)}^{*}}-\frac{\partial w\left(\phi\left(D^{*}-\pi_{L}\right)\right)}{\partial \phi(.)} \cdot \frac{\partial \phi\left(D^{*}-\pi_{L}\right)}{\partial D_{(-)}^{*}}\right) \\
< & 0
\end{aligned}
$$

\footnotetext{
${ }^{20}$ The regulated income $\pi(q)$ attains the maximum at $q_{m}$. Given the assumptions on $\pi(q)$, two quantities in $[0, \bar{q}]$ can yield the same income $I \neq \pi\left(q_{m}\right)$. The regulator will choose the higher quantity as it yields higher consumer surplus. $\phi($.$) is then a function rather than a correspondence.$

${ }^{21}$ If $D^{*}=D^{\text {crit }}=0$ or $D^{*}=L$ and $\Delta W(H L, H, L)=0$, the critical debt level $D^{*}$ will not be differentiable, but we still can define the respective right and left derivatives and obtain the monotonicity result in $(0, L)$.
} 
The second term of the expression above is negative, since $\phi($.$) and w(q)$ are strictly decreasing and concave in $\left[q_{m}, q_{r}\right]$, as presented in Section 3. The sign of the first term also follows from monotonicity of $w(q) .^{22}$

Proof of (i), (ii) and (iii). These parts require the computation of the following derivatives:

$$
\begin{aligned}
& \frac{\partial \Delta W}{\partial \pi_{H}}=-\beta \cdot\left(\frac{\partial w\left(\phi\left(D^{*}-\pi_{H}\right)\right)}{\partial \phi(.)} \cdot \frac{\partial \phi\left(D^{*}-\pi_{H}\right)}{\partial \pi_{H}}\right) \leq 0 \\
& \frac{\partial \Delta W}{\partial \pi_{L}}=(1-\beta) \cdot \alpha+\frac{\partial w\left(\phi\left(D^{*}-\pi_{L}\right)\right)}{\partial \phi(.)} \cdot \frac{\partial \phi\left(D^{*}-\pi_{L}\right)}{\partial \pi_{L}}>0
\end{aligned}
$$

Note that $\partial \Delta W / \partial \pi_{H}=0$ if the income requirement $\pi\left(q_{h}^{D}\right)+\pi_{H}=D^{*}$ in the high state does not bind. The derivatives $\partial D^{*} / \partial \pi_{L}$ and $\partial D^{*} / \partial \pi_{H}$ follow then directly from the IFT, (15), (16) and (17):

$$
\begin{aligned}
& \frac{\partial D^{*}}{\partial \pi_{L}}=-\frac{\partial \Delta W}{\partial \pi_{L}} / \frac{\partial \Delta W}{\partial D^{*}}>0 \\
& \frac{\partial D^{*}}{\partial \pi_{H}}=-\frac{\partial \Delta W}{\partial \pi_{H}} / \frac{\partial \Delta W}{\partial D^{*}} \leq 0
\end{aligned}
$$

For an income level $\bar{\pi},\left|\partial D^{*} / \partial \pi_{L}\right|>\left|\partial D^{*} / \partial \pi_{H}\right|$. This follows from the fact that an increase in $\pi_{L}$ improves both the continuation value at state $\pi_{L}$ and decreases the cost of the quantity reduction $q_{h}^{D^{*}}-q_{l}^{D^{*}}$ at state $\pi_{H}$. An increase in $\pi_{H}$ only increases the cost of the reduction $q_{h}^{D^{*}}-q_{l}^{D^{*}}$ and by a smaller amount than a reduction in $\pi_{L}$ of the same size. Claim (iii) follows immediately by subtracting (18) from (19).

Proof of (iv). I compute first the derivative:

$$
\frac{\partial \Delta W}{\partial \beta}=\alpha \cdot L-\alpha \cdot \pi_{L}-\underset{(-)}{C S_{L}-w\left(\phi\left(D^{*}-\pi_{H}\right)\right)<0}
$$

\footnotetext{
${ }^{22}$ The derivative is presented for the range of $D^{*}$ such that $\pi\left(q_{h}^{D}\right)+\pi_{H}=D^{*}$ is binding. Otherwise, $\partial D^{*}>0$ does no impact the income requirement at $\pi_{H}$ and $\partial \phi\left(\pi\left(q_{r}\right)-\pi_{H}\right) / \partial D^{*}=0$. The sign of $\partial \Delta W / \partial D^{*}$ would not be altered by the effect of the other terms.
} 
where the negative sign follows from the assumption in Section 4 that $w()+.C S_{L}+\alpha \cdot \pi_{L}>\alpha \cdot L$ in the range $\left[q_{m}, q_{r}\right]$ and $q_{m} \leq \phi\left(D^{*}-\pi_{H}\right) \leq q_{r}$. The derivative $\partial D^{*} / \partial \beta$ follows from the IFT, (15) and (20):

$$
\frac{\partial D^{*}}{\partial \beta}=-\frac{\partial \Delta W}{\partial \beta} / \frac{\partial \Delta W}{\partial D^{*}}<0
$$

The negative sign of $\partial D^{*} / \partial \beta$ follows from the fact that a higher probability of the high income state $\pi_{H}$ reduces the expected benefit of ensuring continuation for income state $\pi_{L}$ and increases the expected cost from the quantity distortion at income state $\pi_{H}$.

Proof of (v). As $\alpha$ increases, the objectives of the investors and the regulator become more similar and the regulator weighs higher the income of the firm. If $\pi_{L}+\pi\left(q_{l}^{D}\right)<L$, the increase in $\alpha$ reduces the welfare gain from supporting the firm in the low income state $\pi_{L}$, as the negative difference $\pi_{L}+\pi\left(q_{l}^{D}\right)-L$ receives a greater weight. This fact makes the sign of $\partial \Delta W / \partial \alpha$ ambiguous. However, this effect is negligible for $D^{*} \rightarrow L$ and I can obtain:

$$
\begin{aligned}
\lim _{D^{*} \rightarrow L} \frac{\partial \Delta W}{\partial \alpha} & =\lim _{D^{*} \rightarrow L}\left[(1-\beta) \cdot\left(\pi_{L}+\pi\left(q_{l}^{D^{*}}\right)-L\right)+\beta \cdot\left[\pi\left(q_{l}^{D^{*}}\right)-\pi\left(q_{h}^{D^{*}}\right)\right]\right] \\
& =0+\beta \cdot\left[\pi\left(q_{l}^{L}\right)-\pi\left(q_{h}^{L}\right)\right]>0
\end{aligned}
$$

The application of the IFT, (15) and (21) yields $\partial D^{*} / \partial \alpha>0$.

Proof of (vi). The increase in $C S_{L}$ makes continuation more desirable for the regulator and it will be therefore willing to allow greater quantity distortions without liquidation of the firm. Formally, $\partial D^{*} / \partial C S_{L}>0$ follows from the IFT, (15) and $\partial \Delta W / \partial C S_{L}=(1-\beta)>0$.

\section{Numerical Example}

I study numerically the sensitivity of optimal leverage, value of the firm and social welfare to the relative probability of the low and high income states $(\beta)$ and the income difference between the states $(\Delta \pi)$. I use a simple linear demand $(p(q)=100-5 q)$ and quadratic cost $\left(c(q)=q^{2}\right)$ specification, but it is straightforward to modify the implemented program for a different functional form. The rest of parameters affecting the behavior of the regulator, 
managers and investors take the following values: $\alpha=0.5, K=500, L=500, B=425$, $C S_{H}=1000, C S_{L}=100$, and $\pi_{L}=500$.

In Table 1, I consider three cases for the income difference $\Delta \pi$ that correspond to $\left\{\pi_{H}=1.1 \cdot \pi_{L}, \pi_{H}=1.5 \cdot \pi_{L}, \pi_{H}=2 \cdot \pi_{L}\right\}$. For each of these cases, I present, as a function of probability $\beta$, the managers's choice of debt level $D$ normalized by the liquidation value $(D / L)$, and the relative welfare loss for the regulator $(\Delta W / W)$ and relative gain in firm's value $(\Delta V / V)$ when debt $D$ is used instead of full equity finance. As the low income state becomes less likely $(\beta \rightarrow 1)$ and the income difference bigger $(\Delta \pi \rightarrow 1)$, the regulator stops supporting the firm at the low income state $\left(\pi_{L}\right)$ and the managers limit the use of debt with $D / L<1$. The lower leverage mitigates the welfare losses and reduces the value gain associated to the use of debt. The figures 5, 6 and 7 present these results graphically. I have also studied the effect of increasing private benefits $(B)$ and consumer welfare $\left(C S_{L}\right)$. The results are predictable from Lemma 4 and Proposition 3 and omitted for brevity. 


\section{References}

[1] Aghion, P., and P. Bolton , 1992, An Incomplete Contracts Approach to Financial Contracting, The Review of Economic Studies, Vol. 59, No. 3, pp. 473-494

[2] Albuquerque, R., and H. A. Hopenhayn, 2004, Optimal Lending Contracts and Firm Dynamics, The Review of Economic Studies, Vol. 71, No. 2, pp. 285-315

[3] Alexander, C. P., Zagorin, A., and D. Peterson, Whoops! A \$2 Billion Blunder: Washington Public Power Supply System, Time Magazine, August 8, 1983

[4] Altman, E. I., 1984, A Further Empirical Investigation of the Bankruptcy Cost Question, The Journal of Finance, Vol. 39, pp. 1067-1089

[5] Andrade, G., and S. N. Kaplan, 1998, How Costly is Financial (Not Economic) Distress? Evidence from Highly Leveraged Transactions that Became Distressed, The Journal of Finance, Vol. 53, pp. 1443-1493

[6] Armstrong, M., and D. E. M. Sappington, 2007, Recent Developments in the Theory of Regulation, Handbook of Industrial Organization, Vol. 3, pp. 1557-1700

[7] Baron, D. P., 1989, Design of Regulatory Mechanisms and Institutions, Handbook of Industrial Organization, Vol. 2, pp. 1347-1447

[8] Baron, D. P., and R. B. Myerson, 1982, Regulating a Monopolist with Unknown Costs, Econometrica Vol. 50, No. 4, pp. 911-930

[9] Baxter, N., 1967, Leverage, Risk of Ruin and the Cost of Capital, The Journal of Finance, Vol. 22, pp. 395-403

[10] Boiteux, M., 1956, Sur la gestion des Monopoles Publics astreints a l'equilibre budgetaire, Econometrica, Vol. 24, No. 1, pp. 22-40

[11] Bolton, P., and D. S. Scharfstein, 1990, A Theory of Predation Based on Agency Problems in Financial Contracting, The American Economic Review, Vol. 80, pp. 93-106

[12] Bolton, P., and D. S. Scharfstein, 1996, Optimal Debt Structure and the Number of Creditors, The Journal of Political Economy, Vol. 104, pp. 1-25

[13] Che, Y., K., and J. Sakovics, 2004, A Dynamic Theory of Hold-Up, Econometrica, Vol. 72, pp. $1063-1103$

[14] Che, Y., K., and J. Sakovics, 2008, Hold-Up Problem, The New Palgrave Dictionary of Economics, Second Edition

[15] Dasgupta, S., and V. Nanda, 1993, International Journal of Industrial Organization, Vol. 11, pp. 475-497

[16] Dewatripont, M., and J. Tirole, 1994, A Theory of Debt and Equity: Diversity of Securities and Manager-Shareholder Congruence, The Quarterly Journal of Economics, Vol. 109, No. 4, pp. 1027-1054 
[17] Faure-Grimaud, A., 1997, The Regulation of Predatory Firms, Journal of Economics and Management Strategy, Vol. 6, No. 2, pp. 425-451

[18] Gilbert, R. J., and D. M. Newbery, 1994, The Dynamic Efficiency of Regulatory Constitutions, The RAND Journal of Economics, Vol. 25, pp. 538-554

[19] Hart, O., and J. Moore, 1989, Default and Renegotiation: A Dynamic Model of Debt, MIT mimeo. Published in The Quarterly Journal of Economics, Vol. 113 (1998), No. 1, pp. $1-41$

[20] Haugen, R., and L. Senbet, 1978, The Insignificance of Bankruptcy Costs to the Theory of Optimal Capital Structure, The Journal of Finance, Vol. 33, pp. 383-393

[21] Howe, S., 1982, Utility Security Issues: The Scope of Commission Inquiry, Public Utilities Fortnightly, Vol 110, pp. 61-64

[22] Hotchkiss, E. S., Kose, J., Mooradianc, R. M., and K. S. Thorburn, 2007, Bankruptcy and the Resolution of Financial Distress, Handbook of Empirical Corporate Finance, North Holland Publishing Co.

[23] Jensen, M., 1991, Corporate Control and the Politics of Finance, Journal of Applied Corporate Finance, Vol. 4, pp. 13-33

[24] Jensen, M., and W. R. Meckling, 1976, Theory of the Firm, Managerial Behaviour, Agency Costs and Ownership Structure, Journal of Financial Economics, Vol. 3, pp. 305-360

[25] Joskow, P. L., Bohi, D. R., and F. M. Gollop, 1989, Regulatory Failure, Regulatory Reform, and Structural Change in the Electrical Power Industry, Brookings Papers on Economic Activity, Microeconomics, Vol. 1989, pp. 125-208

[26] Laffont, J. J., and J. Tirole, 1986, Using Cost Observation to Regulate Firms, The Journal of Political Economy, Vol. 94, pp. 614-641

[27] Laffont, J. J., and J. Tirole, 1993, A Theory of Procurement and Regulation, The MIT Press

[28] Lyon, T. P., and J. W. Mayo, 2005, Regulatory Opportunism and Investment Behavior: Evidence from the U.S. Electric Utility Industry, The RAND Journal of Economics, Vol. 36 , pp. $628-644$

[29] Modigliani, F., and M. H. Miller, 1958, The Cost of Capital, Corporation Finance and the Theory of Investment, The American Economic Review, Vol. 48, No. 3, pp. 261-297

[30] Myers, S., 1977, The Determinants of Corporate Borrowing, Journal of Financial Economics, Vol. 5, pp. 147-175

[31] Phillips, C. F., 1988, The Regulation of Public Utilities, Theory and Practice, Public Utilities Report, Inc. 
[32] Pope, D., 2008, Nuclear Implosions: The Rise and Fall of the Washington Public Power Supply System, Cambridge University Press

[33] Pope, D., A Northwest Distaste for Nuclear Power, The Seattle Times, July 31, 2008

[34] Riordan, M. H., 1987, Hierarchical Control and Investment Incentives in Procurement, Working Paper E-87-44, Hoover Institution, Stanford University

[35] Ross, S., 1977, The Determination of Financial Structure: The Incentive Signaling Approach, The Bell Journal of Economics and Management Science, Vol. 8 pp. 23-40

[36] Salant, D. J., and G. A. Woroch, 1992, Trigger Price Regulation, The RAND Journal of Economics, Vol. 23, pp. 29-51

[37] Spiegel, Y., and D. Spulber, 1994, The Capital Structure of Regulated Firms, The RAND Journal of Economics, Vol.25, pp. 424-440

[38] Spiegel, Y., and D. Spulber, 1997, Capital Structure with Counterveiling Incentives, The RAND Journal of Economics Vol. 28, No. 1, pp. 1-24

[39] Taggart, R. A., 1985, Effects of Regulation on Utility Financing: Theory and Evidence, The Journal of Industrial Economics, Vol. 33, pp. 257-276

[40] Thakor, A. V., 1996, Capital Requirements, Monetary Policy, and Aggregate Bank Lending: Theory and Empirical Evidence, The Journal of Finance, Vol. 51, pp. 279-324

[41] Tirole, J., 1986, Procurement and Renegotiation, The Journal of Political Economy, Vol. 94, pp. 235-259

[42] Townsend, R., 1979, Optimal Contracts and Competitive Markets with Costly State Verification, Journal of Economic Theory, Vol. 21, pp. 417-425

[43] Warner, J., 1977, Bankruptcy Costs: Some Evidence, The Journal of Finance, Vol. 32, pp. $337-347$ 
Table 1: Numerical Analysis

\begin{tabular}{llll}
\hline \hline \multicolumn{5}{l}{ Case $1: \Delta \pi=0.1$} \\
\hline$\beta$ & $\Delta W / W$ & $\Delta V / V$ & $D / L$ \\
\hline 0.5 & 0.08 & 7.99 & 1 \\
0.65 & 0.07 & 6.96 & 1 \\
0.85 & 0.06 & 5.93 & 1 \\
0.9 & 0.06 & 5.71 & 1 \\
0.95 & 0.06 & 5.52 & 1 \\
\hline \multicolumn{5}{c}{ Case $2: \Delta \pi=0.5$} \\
$\beta$ & $\Delta W / W$ & $\Delta V / V$ & $D / L$ \\
\hline 0.5 & 0.07 & 2.67 & 1 \\
0.65 & 0.07 & 2.13 & 1 \\
0.85 & 0.06 & 1.68 & 1 \\
0.9 & 0.06 & 1.60 & 1 \\
0.95 & 0.02 & 0.73 & 0.5840 \\
\hline \multicolumn{5}{c}{ Case $3: \Delta \pi=1$} & \\
$\beta$ & $\Delta W / W$ & $\Delta V / V$ & $D / L$ \\
\hline 0.5 & 0.07 & 1.45 & 1 \\
0.65 & 0.06 & 1.14 & 1 \\
0.85 & 0.06 & 0.89 & 1 \\
0.9 & 0.04 & 0.74 & 0.9030 \\
0.95 & 0.02 & 0.38 & 0.5840 \\
\hline
\end{tabular}

Figure 1: Timeline (Base Model)

\begin{tabular}{|c|c|c|c|c|}
\hline $\mathrm{t}=0$ & $t=1$ & $t=2$ & $t=3$ & $\mathrm{t}=4$ \\
\hline $\begin{array}{c}\text { Managers } \\
\text { propose } \\
\text { Capital } \\
\text { Structure }(C S) \text {. }\end{array}$ & $\begin{array}{l}\text { Investors } \\
\text { accept or } \\
\text { reject CS. }\end{array}$ & $\begin{array}{l}\text { Regulator } \\
\text { chooses q. }\end{array}$ & $\begin{array}{l}\text { Controlling } \\
\text { investors } \\
\text { decide on } \\
\text { liquidation }\end{array}$ & $\begin{array}{l}\text { Payoffs are } \\
\text { collected }\end{array}$ \\
\hline
\end{tabular}

Figure 2: Timeline (Model with Income Risk)

\begin{tabular}{|c|c|c|c|c|c|}
\hline $\mathrm{t}=0$ & $\mathrm{t}=1$ & $\mathrm{t}=2$ & $t=3$ & $\mathrm{t}=4$ & $\mathrm{t}=5$ \\
\hline $\begin{array}{c}\text { Managers } \\
\text { propose Capital } \\
\text { Structure (CS). }\end{array}$ & $\begin{array}{l}\text { Investors } \\
\text { accept or } \\
\text { reject CS. }\end{array}$ & $\begin{array}{l}\text { Regulator } \\
\text { chooses q. }\end{array}$ & $\begin{array}{c}\text { Unregulated } \\
\text { profits and } \\
\text { surplus are } \\
\text { realized }\end{array}$ & $\begin{array}{l}\text { Controlling } \\
\text { investors } \\
\text { decide on } \\
\text { liquidation }\end{array}$ & $\begin{array}{l}\text { Payoffs are } \\
\text { collected }\end{array}$ \\
\hline
\end{tabular}


Figure 3: Value of Debt (Example 1 for Model with Income Risk)

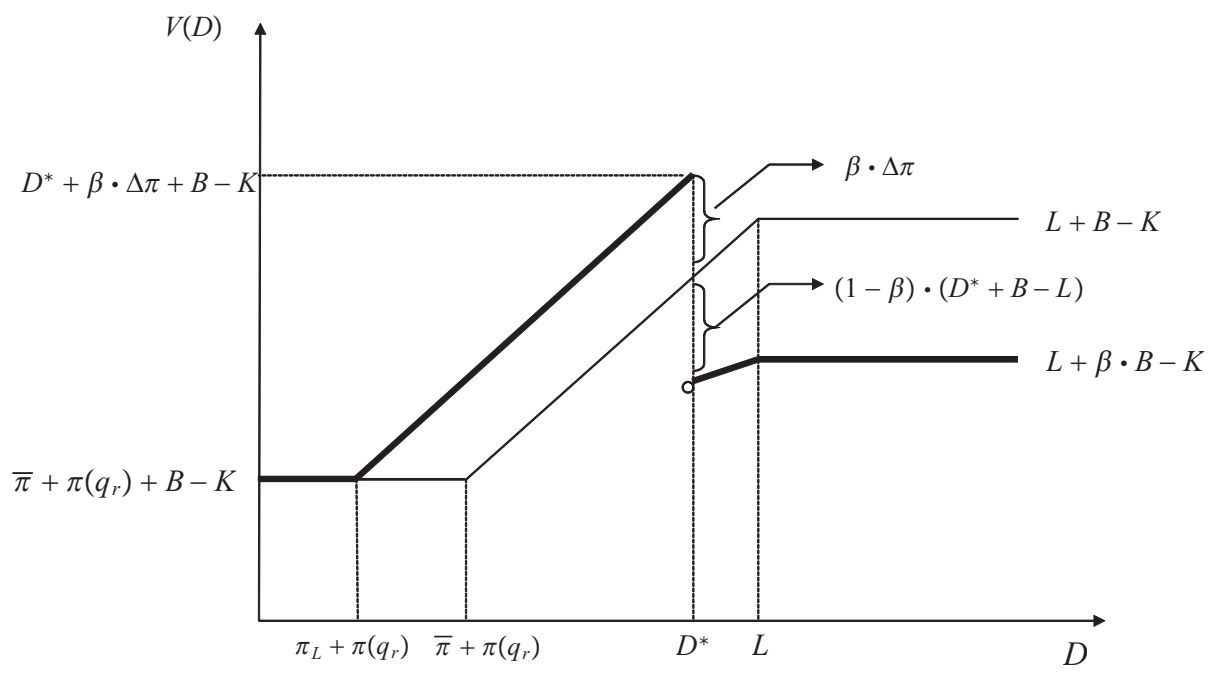

Figure 4: Value of Debt (Example 2 for Model with Income Risk)

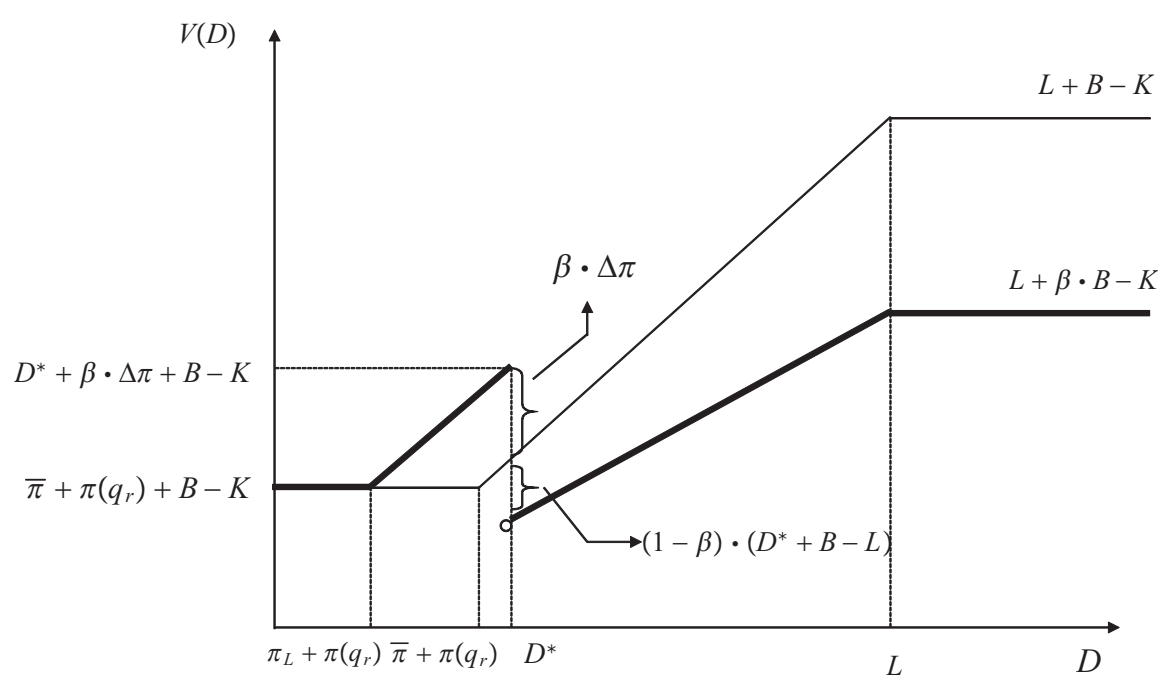


Figure 5: Numerical Example $\left(\Delta \pi=0.1 \cdot \pi_{L}\right)$

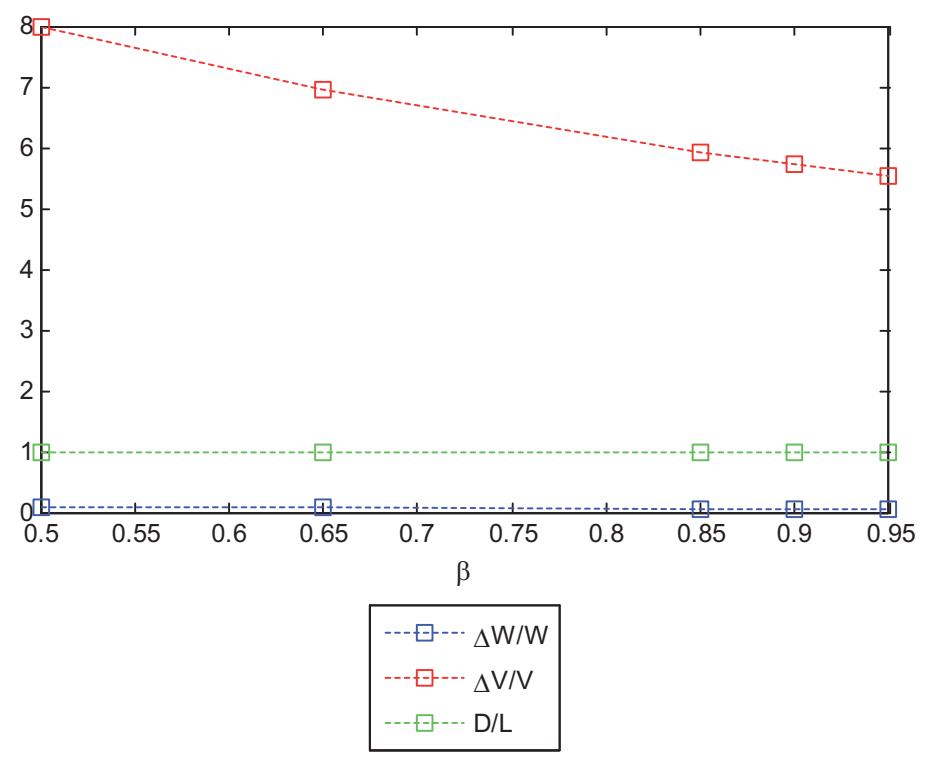

Note: $\beta$ represents the probability of the high income state. $\Delta W / W$ and $\Delta V / V$ represent the relative welfare loss and gain in firm's value from use of leverage $D / L$.

Figure 6: Numerical Example $\left(\Delta \pi=0.5 \cdot \pi_{L}\right)$

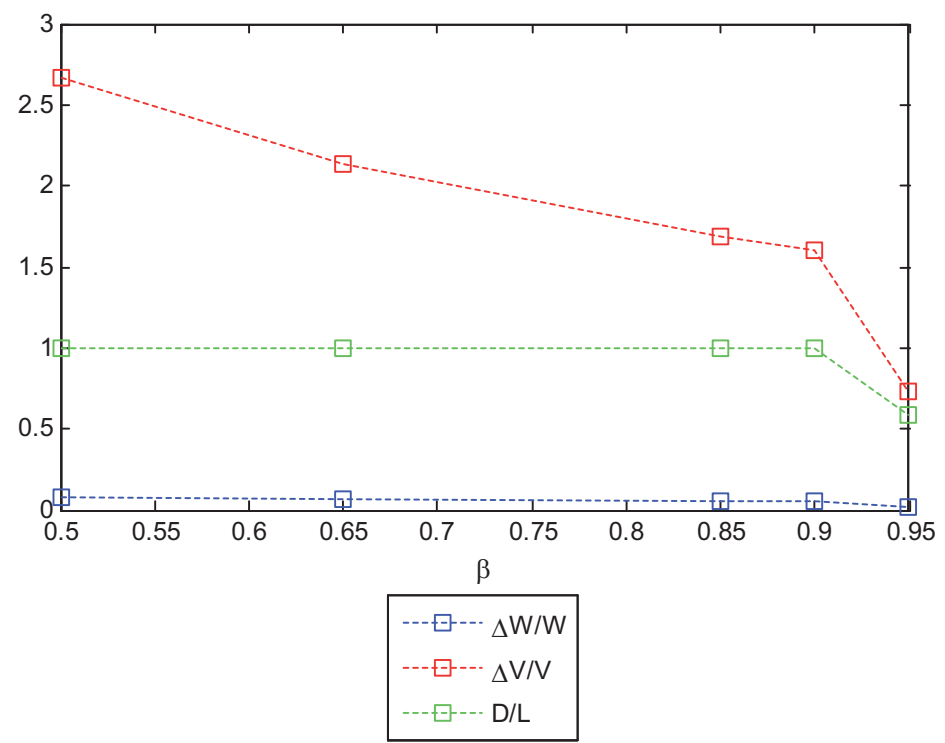

Note: $\beta$ represents the probability of the high income state. $\Delta W / W$ and $\Delta V / V$ represent the relative welfare loss and gain in firm's value from use of leverage $D / L$. 
Figure 7: Numerical Example $\left(\Delta \pi=1 \cdot \pi_{L}\right)$

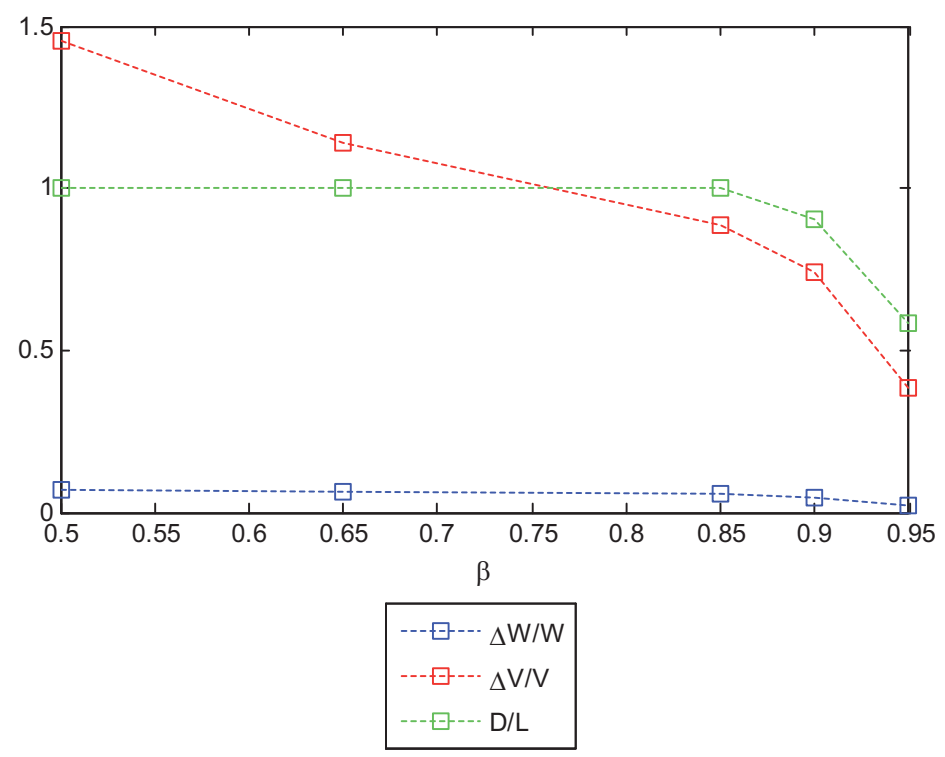

Note: $\beta$ represents the probability of the high income state. $\Delta W / W$ and $\Delta V / V$ represent the relative welfare loss and gain in firm's value from use of leverage $D / L$. 


\section{BANCO DE ESPAÑA PUBLICATIONS}

\section{WORKING PAPERS ${ }^{1}$}

1032 GABE J. DE BONDT, TUOMAS A. PELTONEN AND DANIEL SANTABÁRBARA: Booms and busts in China's stock market: Estimates based on fundamentals.

1033 CARMEN MARTÍNEZ-CARRASCAL AND JULIAN VON LANDESBERGER: Explaining the demand for money by nonfinancial corporations in the euro area: A macro and a micro view.

1034 CARMEN MARTÍNEZ-CARRASCAL: Cash holdings, firm size and access to external finance. Evidence for the euro area.

1035 CÉSAR ALONSO-BORREGO: Firm behavior, market deregulation and productivity in Spain.

1036 OLYMPIA BOVER: Housing purchases and the dynamics of housing wealth.

1037 DAVID DE ANTONIO LIEDO AND ELENA FERNÁNDEZ MUÑOZ: Nowcasting Spanish GDP growth in real time: "One and a half months earlier".

1038 FRANCESCA VIANI: International financial flows, real exchange rates and cross-border insurance.

1039 FERNANDO BRONER, TATIANA DIDIER, AITOR ERCE AND SERGIO L. SCHMUKLER: Gross capital flows: dynamics and crises.

1101 GIACOMO MASIER AND ERNESTO VILLANUEVA: Consumption and initial mortgage conditions: evidence from survey data.

1102 PABLO HERNÁNDEZ DE COS AND ENRIQUE MORAL-BENITO: Endogenous fiscal consolidations.

1103 CÉSAR CALDERÓN, ENRIQUE MORAL-BENITO AND LUIS SERVÉN: Is infrastructure capital productive? A dynamic heterogeneous approach.

1104 MICHAEL DANQUAH, ENRIQUE MORAL-BENITO AND BAZOUMANA OUATTARA: TFP growth and its determinants: nonparametrics and model averaging.

1105 JUAN CARLOS BERGANZA AND CARMEN BROTO: Flexible inflation targets, forex interventions and exchange rate volatility in emerging countries.

1106 FRANCISCO DE CASTRO, JAVIER J. PÉREZ AND MARTA RODRÍGUEZ VIVES: Fiscal data revisions in Europe.

1107 ANGEL GAVILÁN, PABLO HERNÁNDEZ DE COS, JUAN F. JIMENO AND JUAN A. ROJAS: Fiscal policy, structural reforms and external imbalances: a quantitative evaluation for Spain.

1108 EVA ORTEGA, MARGARITA RUBIO AND CARLOS THOMAS: House purchase versus rental in Spain.

1109 ENRIQUE MORAL-BENITO: Dynamic panels with predetermined regressors: likelihood-based estimation and Bayesian averaging with an application to cross-country growth.

1110 NIKOLAI STÄHLER AND CARLOS THOMAS: FiMod - a DSGE model for fiscal policy simulations.

1111 ÁLVARO CARTEA AND JOSÉ PENALVA: Where is the value in high frequency trading?

1112 FILIPA SÁ AND FRANCESCA VIANI: Shifts in portfolio preferences of international investors: an application to sovereign wealth funds.

1113 REBECA ANGUREN MARTÍN: Credit cycles: Evidence based on a non-linear model for developed countries.

1114 LAURA HOSPIDO: Estimating non-linear models with multiple fixed effects: A computational note.

1115 ENRIQUE MORAL-BENITO AND CRISTIAN BARTOLUCCI: Income and democracy: Revisiting the evidence.

1116 AGUSTÍN MARAVALL HERRERO AND DOMINGO PÉREZ CAÑETE: Applying and interpreting model-based seasonal adjustment. The euro-area industrial production series.

1117 JULIO CÁCERES-DELPIANO: Is there a cost associated with an increase in family size beyond child investment? Evidence from developing countries.

1118 DANIEL PÉREZ, VICENTE SALAS-FUMÁS AND JESÚS SAURINA: Do dynamic provisions reduce income smoothing using loan loss provisions?

1119 GALO NUÑO, PEDRO TEDDE AND ALESSIO MORO: Money dynamics with multiple banks of issue: evidence from Spain 1856-1874.

1120 RAQUEL CARRASCO, JUAN F. JIMENO AND A. CAROLINA ORTEGA: Accounting for changes in the Spanish wage distribution: the role of employment composition effects.

1. Previously published Working Papers are listed in the Banco de España publications catalogue. 
1121 FRANCISCO DE CASTRO AND LAURA FERNÁNDEZ-CABALLERO: The effects of fiscal shocks on the exchange rate in Spain.

1122 JAMES COSTAIN AND ANTON NAKOV: Precautionary price stickiness.

1123 ENRIQUE MORAL-BENITO: Model averaging in economics.

1124 GABRIEL JIMÉNEZ, ATIF MIAN, JOSÉ-LUIS PEYDRÓ AND JESÚS SAURINA: Local versus aggregate lending channels: the effects of securitization on corporate credit supply.

1125 ANTON NAKOV AND GALO NUÑO: A general equilibrium model of the oil market.

1126 DANIEL C. HARDY AND MARÍA J. NIETO: Cross-border coordination of prudential supervision and deposit guarantees.

1127 LAURA FERNÁNDEZ-CABALLERO, DIEGO J. PEDREGAL AND JAVIER J. PÉREZ: Monitoring sub-central government spending in Spain.

1128 CARLOS PÉREZ MONTES: Optimal capital structure and regulatory control.

\begin{tabular}{|r|c|}
\hline & Unidad de Publicaciones \\
BANCODEESPANA & Alcalá 522, 28027 Madrid \\
Eurosistema & Telephone +34 913386363. Fax +34913386488 \\
& E-mail: publicaciones@bde.es \\
www.bde.es
\end{tabular}

